\title{
Catalytic Oxidation of Synthesis Gas on Platinum at Low Temperatures for Power Generation Applications
}

\author{
Junjie Chen * ${ }^{(1)}$, Longfei Yan ${ }^{(0)}$, Wenya Song ${ }^{(\mathbb{D})}$ and Deguang $X u^{(\mathbb{D})}$ \\ Department of Energy and Power Engineering, School of Mechanical and Power Engineering, \\ Henan Polytechnic University, Jiaozuo 454000, Henan, China; feitpj@163.com (L.Y.); wentpj@163.com (W.S.); \\ gaotpj@163.com (D.X.) \\ * Correspondence: comcjj@163.com or cjj@hpu.edu.cn; Tel.: +86-151-3805-7627
}

Received: 19 May 2018; Accepted: 14 June 2018; Published: 15 June 2018

\begin{abstract}
This paper addresses the issues related to the low-temperature catalytic oxidation of synthesis gas at high pressures under lean-burn conditions. The purpose of this study is to explore the mechanism responsible for the interplay between carbon monoxide and hydrogen during their combined oxidation process. Particular attention is given to the temperature range from 500 to $770 \mathrm{~K}$, which is relevant to the catalyst inlet temperature encountered in catalytic combustion gas turbine systems. Computational fluid dynamics simulations were performed by using a numerical model with detailed chemistry and transport. Reaction path analysis was conducted, and the rate-determining step in the reaction mechanism was finally identified. It was shown that there is a strong interplay between carbon monoxide and hydrogen during the combined oxidation process. The addition of hydrogen causes a great change in the adsorbed species on the surface of the catalyst. At temperatures as low as $600 \mathrm{~K}$, the presence of hydrogen makes the active surface sites more available for adsorption, thus promoting the catalytic oxidation of carbon monoxide. The coupling steps between the two components make a small contribution to the promoting effect. At temperatures below $520 \mathrm{~K}$, the presence of hydrogen inhibits the catalytic oxidation of carbon monoxide due to the competitive effect of hydrogen on oxygen adsorption.
\end{abstract}

Keywords: catalytic combustion; micro-combustion; low-temperature oxidation; power generation systems; synthesis gas; numerical simulations; catalytic combustion gas turbines; computational fluid dynamics

\section{Introduction}

There has been an increasing interest in the catalytic oxidation of synthesis gas, also known as syngas, due to its potential applications in power generation systems [1-4]. A full understanding of the mechanism of this reaction will be beneficial to develop other fuel processing technologies [5,6], such as preferential oxidation, partial oxidation, and water-gas shift. All of these processes share the same fundamental mechanism of carbon monoxide and hydrogen oxidation, adsorption, and desorption, and thus the same synergetic effect arising from the use of multiple fuels. This synergism is usually referred to in the literature as a "carbon monoxide-hydrogen coupling".

Syngas is of interest for its promising applications in large-scale and portable power generation systems [7-10] and fuel cell gas turbine hybrid systems [11,12]. Power generation utilizing catalytic combustion has emerged as a promising alternative for these syngas-fueled systems [13-16]. Catalytic combustion can be achieved at much lower temperatures than conventional gas-phase combustion $[17,18]$, resulting in lower emissions. Furthermore, catalytic combustion systems can be designed with very simple geometries, which can dramatically simplify the design and reduce the cost $[18,19]$. Consequently, there is an increasing interest in developing the ability of applying this 
technology to power generation systems [20-23]. Although significant progress has been made in this field [24-28], more fundamental research is needed to build confidence for the practical implementation of this technology.

Numerous efforts have been focused on understanding the mechanistic aspects of the catalytic oxidation of either carbon monoxide or hydrogen over noble metal catalysts. Catalytic oxidation of these individual fuels is comparatively well understood at present. Additionally, considerable progress has been made in the gas-phase combustion of syngas $[29,30]$. However, there is still a lack of understanding of the catalytic oxidation of syngas, which is an issue of both practical concern and fundamental interest [31,32]. This oxidation process is presently receiving considerable attention [33-39], especially in the process design and development.

Unfortunately, the mechanism of the catalytic oxidation of syngas under the typical conditions of gas-turbines has not yet been fully understood [39-42], and there still remain a series of open questions that need to be further clarified [43-47]. There is a growing interest in developing a better understanding of the reaction mechanism [36-39]. This interest is motivated by the need to improve the performance and efficiency of currently operating power generation systems, as well as to reduce the pollutant emissions generated in the oxidation process. However, a fundamental understanding of the mechanism at the molecular level is still lacking, due to the complexity of this reaction. A crucial aspect is the synergetic effect arising from the "carbon monoxide-hydrogen coupling", which cannot currently be captured with the reaction mechanism available in the literature. The existing mechanisms do not adequately model the interplay between carbon monoxide and hydrogen during the combined oxidation process [36,37], especially at low temperatures.

It is necessary to understand the mechanism of the catalytic oxidation of syngas due to its potential application in both large-scale and portable power generation systems [7-10,16]. Considerable progress has been made in the mechanism of the reaction at moderate-to-high temperatures, with an aim toward identifying the complex interplay between carbon monoxide and hydrogen during their combined oxidation process [2,3]. Recently, there have been several research activities directed towards understanding the mechanism of the reaction at low temperatures, which is of great significance in the field of catalytic combustion gas turbine systems $[7,8,10,16]$. However, the mechanism at low temperatures still remains controversial, and there is conflicting experimental data reported in the literature. Is this oxidation process simple? Recent experiments have demonstrated that the low-temperature process is inherently complex and is critically dependent on operating conditions [36,37]. Changes in temperature by even $50 \mathrm{~K}$ can greatly affect the mechanism $[36,37]$. Consequently, it is necessary to clarify the mechanism underlying the syngas catalytic oxidation process in order to investigate this phenomenon thoroughly.

It has been reported that hydrogen has a promoting effect on the catalytic oxidation of carbon monoxide [37]. However, there is still uncertainty as to whether the promoting effect is due to the result of a change in the reaction kinetics of carbon monoxide oxidation by the production of intermediate species, or the temperature rise caused by hydrogen oxidation. The nature of this oxidation reaction is relatively complex, making it difficult to accurately determine the role of hydrogen in the mechanism. A slight difference in the reaction mechanism may eventually lead to the opposite results, with the predicted promotion or inhibition of the role of hydrogen [7]. In addition to the promoting and inhibiting roles played by hydrogen, a neutral effect has been reported recently in the literature [8]. One important research finding is that there is a transition temperature, below which the presence of hydrogen has an inhibiting effect on the catalytic oxidation of carbon monoxide over platinum $[10,16]$. This transition temperature is approximately $550 \mathrm{~K}$, as reported recently by Zheng et al. [10,16], where the mechanism responsible for this inhibiting effect has also been identified.

This paper addresses the issues related to the low-temperature catalytic oxidation of syngas over platinum at high pressures under lean-burn conditions. This paper mainly focuses on the temperature range from 500 to $770 \mathrm{~K}$, which is relevant to the catalyst inlet temperature encountered in catalytic combustion large gas turbine systems (catalyst inlet temperatures as low as 
$620 \mathrm{~K}[48-50]$ ) and recuperated micro-turbine systems (catalyst inlet temperatures $600-700 \mathrm{~K}[10,16])$, as well as the part-load and idling operation in gas turbine systems (catalyst inlet temperatures 500-600 K [10]). A two-dimensional numerical model with detailed chemistry and transport was developed, and detailed modeling of the low-temperature catalytic oxidation system was performed. The importance of mass-transfer limitations in the oxidation system was also examined. A detailed description is made for the low-temperature catalytic oxidation process, based on the reaction mechanism described in the literature $[10,16]$. The objective of this paper is to understand the mechanism of the low-temperature catalytic oxidation of syngas for power generation applications. Of special interest is to gain insight into the interplay between carbon monoxide and hydrogen during their combined oxidation process at low temperatures.

\section{Model Development}

Computational fluid dynamics integrated with detailed kinetic models is an effective tool for revealing the physical and chemical phenomena involved in the reaction process and subsequently understanding the underlying mechanism [51,52]. In the following sections, a two-dimensional computational fluid dynamics model with detailed chemistry and transport is developed in order to accurately describe the low-temperature catalytic oxidation process of syngas over platinum.

\subsection{Geometric Model}

In terms of combustion systems, gas turbine manufacturers have been developing various designs. Most of them are based on the so-called hybrid catalytic combustion concept [50,53]. A schematic diagram of the catalytic reactor in a catalytic combustion gas turbine system is illustrated in Figure 1. In this design, fuel and combustion air are premixed in an upstream section: then, only a fraction of the fuel is oxidized in the catalytic section, while the remainder is burned downstream the catalyst in gas-phase combustion mode $[50,53]$. The present work focuses on the low-temperature oxidation reaction taking place in the catalytic reactor.

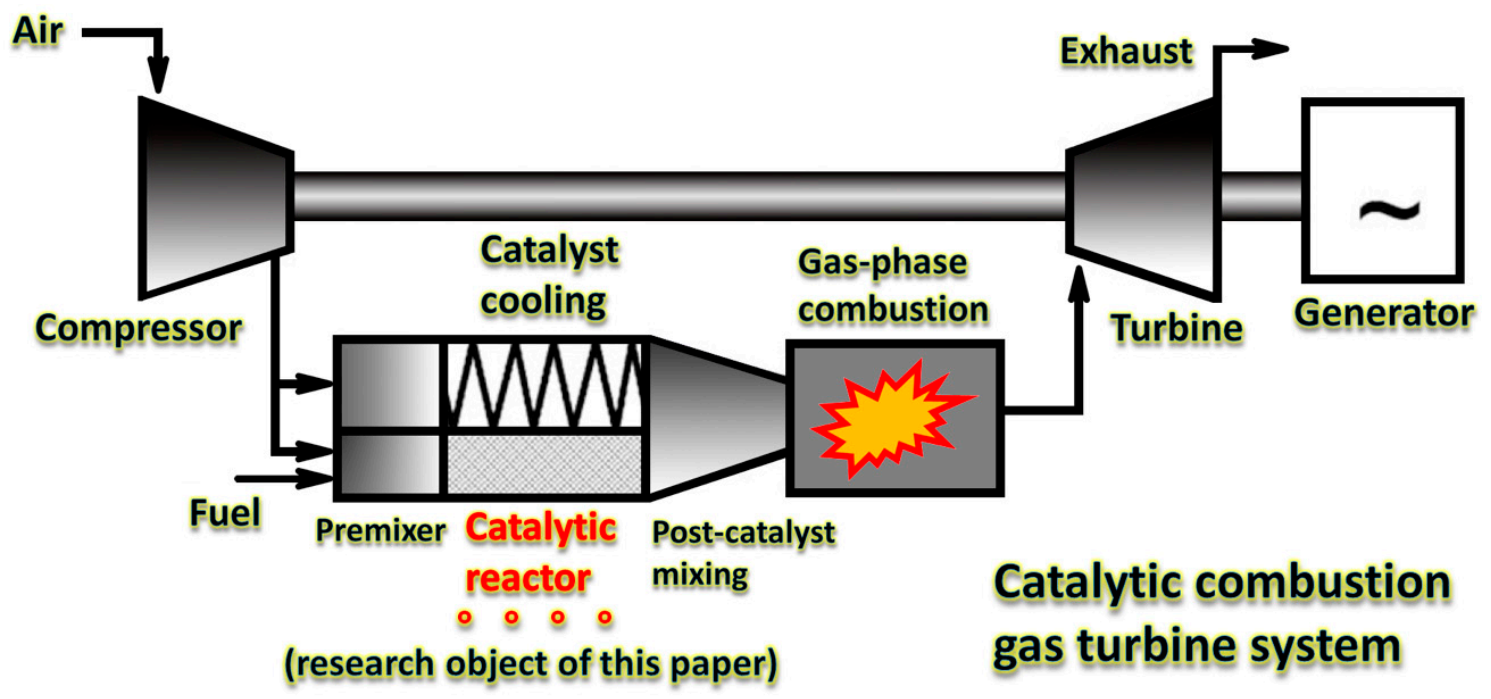

Figure 1. Schematic diagram of the catalytic reactor in a catalytic combustion gas turbine system. The catalytic reactor is the research object of this paper.

Specifically, the reaction system considered in this paper is the low-temperature oxidation of syngas in catalytic plate microreactors. A single channel model is developed to describe the low-temperature oxidation process occurring in the reactor. The single channel model, as usual, assumes that it is representative of all of the channels, and that all channels of the reactor behave essentially alike. A schematic diagram of the single-channel catalytic microreactor being considered is 
illustrated in Figure 2. In this design, the reactor consists of two parallel plates coated with a supported platinum catalyst. The reactor is $6.0 \mathrm{~mm}$ long, the wall thickness is $0.2 \mathrm{~mm}$, and the gap distance between the two parallel plates is $0.8 \mathrm{~mm}$. Plates at distances of an order of millimeters can minimize heat and mass transfer resistances. Such an arrangement would be particularly advantageous for chemical kinetics studies. The parallel plates are coated with a thin layer of washcoat containing a supported platinum catalyst, and the washcoat thickness is $0.08 \mathrm{~mm}$. Due to the aspect ratio, the reactor is modeled as a two-dimensional system.

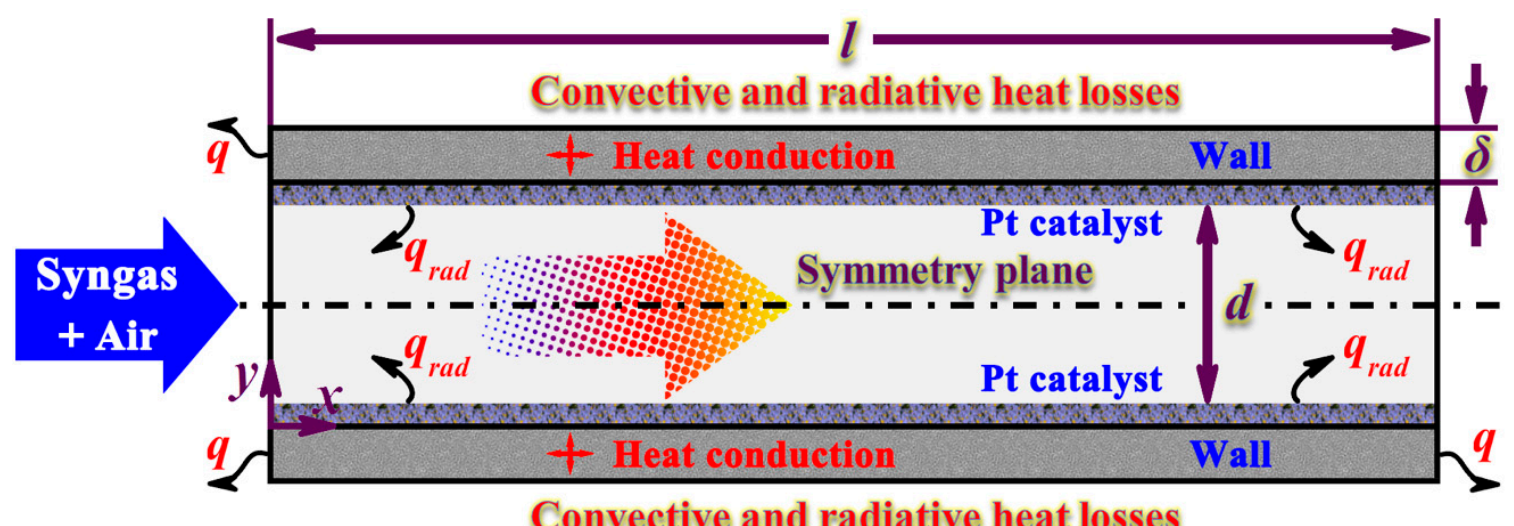

Figure 2. Schematic diagram of the single-channel catalytic microreactor (not to scale for ease of visualization). Symmetry allows the simulation of only half of the system.

The primary techniques for the catalytic combustion of syngas and some of the catalysts used have been briefly reviewed by Mantzaras [13]. Both noble metal and metal oxide catalysts show great promise for application in power generation systems, but the former is the best choice $[13,28]$. The catalyst considered here is platinum due to its well-studied kinetics. In particular, platinum still has sufficient catalytic activity over the temperature range of practical interest.

The existence of mass-transfer limitation in catalytic reactors can hinder the determination of intrinsic reaction kinetics. Upon catalyst light-off, it is often difficult to obtain isothermal conditions due to the significant temperature gradients arising from the exothermicity of the oxidation reaction. Nonetheless, high rates of heat and mass transfer are possible in microreactors, allowing the oxidation reaction to be performed under nearly isothermal conditions, which will be discussed in detail later. It is therefore possible to achieve a better transport performance in the system and thus to investigate the intrinsic kinetics of the highly exothermic reaction. Additionally, a simpler, small-scale system can not only greatly eliminate the heat and mass transfer resistances, which is necessary to understand the reaction mechanism underlying the combined oxidation process, but also provide valuable insights into how its pathways can be optimized [54-58]. Furthermore, it can also enable easy integration with other energy harvesting devices, with fewer heat transfer boundary layers being involved.

\subsection{Mathematical Model}

The following assumptions are made: ideal gas behavior is assumed, a steady state operation is considered for the reactor, the pressure drop along the flow channel is negligible, radiative heat transfer in the gas phase is negligible in comparison with that between the parallel surfaces, and the flow is laminar given that the Reynolds number is less than 280. Under these assumptions, the governing equations are solved by using commercial computational fluid dynamics software ANSYS Fluent ${ }^{\circledR}$ (Release 16.0, ANSYS Inc., Canonsburg, PA, USA) [59]. In addition, detailed reaction mechanisms and transport are included in the numerical model in order to provide an accurate description of 
the low-temperature catalytic oxidation process. The steady-state continuity, momentum, energy, and species equations in the fluid phase are summarized as follows:

$$
\begin{gathered}
\frac{\partial(\rho u)}{\partial x}+\frac{\partial(\rho v)}{\partial y}=0 \\
\frac{\partial(\rho u u)}{\partial x}+\frac{\partial(\rho v u)}{\partial y}+\frac{\partial p}{\partial x}-\frac{\partial}{\partial x}\left[2 \mu \frac{\partial u}{\partial x}-\frac{2}{3} \mu\left(\frac{\partial u}{\partial x}+\frac{\partial v}{\partial y}\right)\right]-\frac{\partial}{\partial y}\left[\mu\left(\frac{\partial u}{\partial y}+\frac{\partial v}{\partial x}\right)\right]=0, \\
\frac{\partial(\rho u v)}{\partial x}+\frac{\partial(\rho v v)}{\partial y}+\frac{\partial p}{\partial y}-\frac{\partial}{\partial x}\left[\mu\left(\frac{\partial v}{\partial x}+\frac{\partial u}{\partial y}\right)\right]-\frac{\partial}{\partial y}\left[2 \mu \frac{\partial v}{\partial y}-\frac{2}{3} \mu\left(\frac{\partial u}{\partial x}+\frac{\partial v}{\partial y}\right)\right]=0, \\
\frac{\partial(\rho u h)}{\partial x}+\frac{\partial(\rho v h)}{\partial y}+\frac{\partial}{\partial x}\left(\rho \sum_{k=1}^{K_{g}} Y_{k} h_{k} V_{k, x}-\lambda_{g} \frac{\partial T}{\partial x}\right)+\frac{\partial}{\partial y}\left(\rho \sum_{k=1}^{K_{g}} Y_{k} h_{k} V_{k, y}-\lambda_{g} \frac{\partial T}{\partial y}\right)=0, \\
\frac{\partial\left(\rho u Y_{k}\right)}{\partial x}+\frac{\partial\left(\rho v Y_{k}\right)}{\partial y}+\frac{\partial}{\partial x}\left(\rho Y_{k} V_{k, x}\right)+\frac{\partial}{\partial y}\left(\rho Y_{k} V_{k, y}\right)-\dot{\omega}_{k} W_{k}=0, k=1, \ldots, K_{g} .
\end{gathered}
$$

where the species diffusion velocity, $V_{k, x}$ and $V_{k, y}$, are given by

$$
\vec{V}_{k}=-D_{k, m} \nabla\left[\ln \left(\frac{Y_{k} \bar{W}}{W_{k}}\right)\right]+\left[\frac{D_{k}^{T} W}{\rho Y_{k} \bar{W}}\right] \nabla(\ln T) .
$$

The ideal gas law and the caloric equation of state are used respectively

$$
p=\frac{\rho R T}{\bar{W}} \text { and } h_{k}=h_{k}^{o}\left(T_{o}\right)+\int_{T_{o}}^{T} c_{p, k} d T
$$

The coverage equation of the species on the surface of the catalyst is given by

$$
\sigma_{m} \frac{\dot{s}_{m}}{\Gamma}=0, m=K_{g}+1, \ldots, K_{g}+K_{s}
$$

The energy equation in the wall is given by

$$
\frac{\partial}{\partial x}\left(\lambda_{s} \frac{\partial T}{\partial x}\right)+\frac{\partial}{\partial y}\left(\lambda_{s} \frac{\partial T}{\partial y}\right)=0
$$

In this study, nearly isothermal wall conditions are considered in an attempt to decouple kinetic effects from thermal effects. This is achieved by assuming a highly conductive material with a wall thermal conductivity of $80 \mathrm{~W} /(\mathrm{m} \cdot \mathrm{K})$. Under these conditions, numerical simulations are subsequently carried out to focus on the kinetic effects rather than the thermal effects.

The boundary condition for the gaseous species at the fluid-washcoat interface is given by

$$
\left(\rho Y_{k} V_{k, y}\right)_{\text {interface }}+\eta F_{\text {cat } / g e o} W_{k}\left(\dot{s}_{k}\right)_{\text {interface }}=0, k=1, \ldots, K_{g} .
$$

where $F_{\text {cat/geo }}$ is the catalyst/geometric surface area [60].

In order to accurately describe the diffusional limitation in the catalyst washcoat, the model is simplified by using the concept of effectiveness factor, defined as

$$
\eta=\frac{\dot{s}_{i, e f f}}{\dot{s}_{i}}=\frac{\tanh (\Phi)}{\Phi}
$$


where $\Phi$ is the Thiele modulus, defined as

$$
\Phi=\delta_{\text {catalyst }}\left(\frac{\dot{s}_{i} \gamma}{D_{i, e f f} C_{i, \text { interface }}}\right)^{0.5} .
$$

The effective diffusion coefficient can be expressed as

$$
\frac{1}{D_{i, e f f}}=\frac{\tau_{p}}{\varepsilon_{p}}\left(\frac{1}{D_{i, \text { molecular }}}+\frac{1}{D_{i, \text { Knudsen }}}\right)
$$

A parallel pore model is employed to describe the porous structure of the catalyst washcoat. In the present work, a mean pore diameter of $20 \mathrm{~nm}$, together with a porosity of 0.5 and a tortuosity factor of 3, are considered. The Knudsen diffusion coefficient is given by

$$
D_{i, \text { Knudsen }}=\frac{d_{\text {pore }}}{3} \sqrt{\frac{8 R T}{\pi W_{i}}} .
$$

The boundary condition of the energy equation at the fluid-washcoat interface is given by

$$
\dot{q}_{\text {rad }}-\lambda_{g}\left(\frac{\partial T}{\partial y}\right)_{\text {interface- }}+\lambda_{s}\left(\frac{\partial T}{\partial y}\right)_{\text {interface+ }}+\sum_{k=1}^{K_{g}}\left(\dot{s}_{k} h_{k} W_{k}\right)_{\text {interface }}=0 .
$$

Despite the low wall temperatures examined in this paper, the effect of the radiative heat transfer between the parallel surfaces is included in the numerical model. The net radiation method for diffuse-gray areas is employed to obtain expressions for the radiative heat transfer between the parallel surfaces. The emissivity of each element of the surfaces is assumed to be 0.8 [61].

Heat losses from the outer edge of the wall to the surroundings are accounted for:

$$
q=h_{o}\left(T_{w, o}-T_{a m b}\right)+\varepsilon_{s-\infty} F_{s-\infty} \sigma\left(T_{w, o}^{4}-T_{a m b}^{4}\right) .
$$

The external heat loss coefficient, $h_{0}$, is assumed to be $20 \mathrm{~W} /\left(\mathrm{m}^{2} \cdot \mathrm{K}\right)[61]$.

\subsection{Chemical Kinetics}

The oxidation reaction can take place both on the surface of the catalyst and in the gas phase. To better understand the mechanism of the low-temperature catalytic oxidation reaction at the molecular level, it is important to model simultaneously the surface and gas-phase chemistry. Furthermore, heat and mass transfer effects must also be incorporated into the numerical model to accurately predict the operation of the reactor [62].

A detailed chemical kinetic mechanism has been developed by Zheng et al. [10,16] to accurately describe the catalytic oxidation process of syngas over platinum. The kinetic mechanism is used in this paper, and the development process is briefly described as follows. The oxidation reaction on the surface of the catalyst is preliminarily modeled by using the mechanism developed by Deutschmann et al. [63]. The mechanism accounts for the adsorbed species on the surface of the catalyst, as well as the reaction intermediates formed during the oxidation reaction, and it has been presented in a format compatible to CHEMKIN codes. Twenty-four elementary reactions, eleven species on the surface of the catalyst, and seven species in the gas phase are considered in this mechanism. The mechanism has been extensively validated, making the predictions very reliable. Methane-involved elementary reactions are not considered in the surface chemistry, since they are irrelevant to the topic of this paper. This mechanism is augmented with the additional mechanistic steps involving the adsorbed intermediate formate $\left(\mathrm{HCOO}^{*}\right)$, which are taken from Koop and Deutschmann [64]. The resulting surface reaction mechanism consists of nine species on the surface of 
the catalyst and eight species in the gas phase involved in twenty-seven elementary reactions, which will be discussed in detail later in this paper. The final chemical kinetic mechanism is relatively simple and the kinetic stiffness problem is not especially severe.

The oxidation reaction in the gas phase is modeled by using the homogeneous mechanism developed by Li et al. [65], consisting of thirteen species involved in thirty-six reversible elementary reactions. The hydrogen-oxygen chemistry part in this mechanism has been updated on the basis of the latest experimental data available in the literature [66]. The gas-phase chemistry included in the model deserves special attention, which will also be discussed in detail later.

Homogeneous and heterogeneous reaction rates are handled by CHEMKIN [67] and Surface-CHEMKIN [68] subroutines, respectively, while the transport properties for multicomponent gas mixtures are treated by using the CHEMKIN transport database [69].

\subsection{Computation Scheme}

The reactor is discretized using a structured mesh. The mesh is composed of rectangular elements, with finer node spacing in the washcoat region than that at the centerline. In order to achieve a sufficient accuracy and to limit the computer time requirements, meshes with different nodal densities are examined and the optimal node density and spacing are determined. Unless otherwise stated, all the solutions presented in the present work are achieved using a mesh consisting of 20,000 nodes. A mesh independence test is also performed. Figure 3 shows the transverse profiles of carbon monoxide and hydrogen mole fractions for some of the meshes used. As the mesh density increases, there is a convergence of the solution. The coarsest mesh, consisting of 1250 nodes in total, fails to accurately capture the carbon monoxide concentration in the vicinity of the catalytic surface. Solutions obtained with meshes consisting of tens of thousands of nodes are reasonably accurate. Larger mesh densities, up to 80,000 nodes in total, offer no obvious advantage.

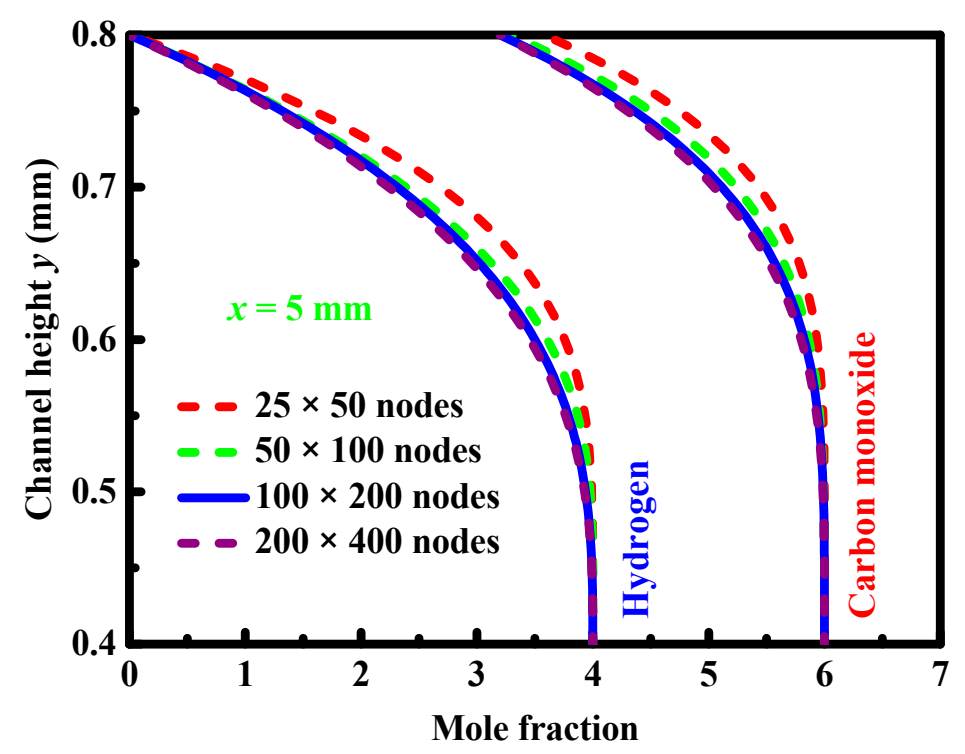

Figure 3. Example of the transverse profiles of carbon monoxide and hydrogen mole fractions for meshes with different nodal densities. The parameters used are $\varphi=0.167, \beta_{\mathrm{H}_{2}}=4.0 \%, \beta_{\mathrm{CO}}=6.0 \%$, $\beta_{\mathrm{O}_{2}}=30.0 \%, \beta_{\mathrm{N}_{2}}=60.0 \%, T_{\text {in }}=300 \mathrm{~K}, u_{\text {in }}=2.0 \mathrm{~m} / \mathrm{s}$, and $p_{\text {in }}=0.6 \mathrm{MPa}$.

At the centerline between the two plates, a symmetry boundary condition is applied. At the fluid-washcoat interface, the no-slip boundary condition is applied. The temperature dependence of physical properties of the species in the mixture is accounted for. The mixture properties such as thermal conductivity, viscosity, and specific heat are obtained from the local mass-fraction-weighted average properties of all the species in the gas phase. The conservation equations are solved using 
a segregated solver with an under-relaxation factor control method. The solution is deemed to be converged as the residuals of the conservation equations are less than $10^{-6}$. Due to the inherent stiffness of the chemistry, convergence of the solution is usually difficult. Figure 4 shows the values of the residuals of the conservation equations after each iteration. The convergence criterion is satisfied after approximately 700 iterations.

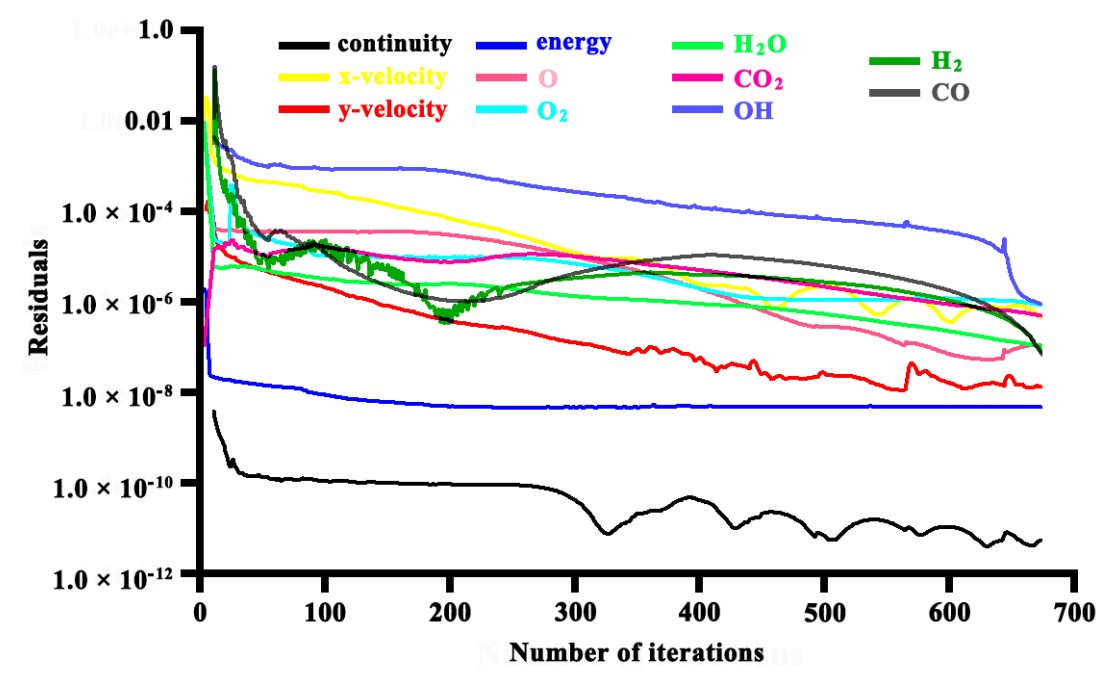

Figure 4. Values of the residuals of the conservation equations after each iteration. The mesh consists of 100 axial nodes by 200 transverse nodes. The rest of the parameters used are the same as those shown in Figure 3.

\section{Results and Discussion}

\subsection{Surface Reaction Mechanism}

Both reactor design and process optimization require an accurate knowledge of the chemistry during the low-temperature catalytic oxidation process of syngas. However, the chemistry is inherently complex and critically depends on the carbon monoxide oxidation, the hydrogen oxidation, and coupling reactions between them $[70,71]$. It is therefore necessary to develop a mechanism that can simultaneously describe all of these processes in order to accurately capture the underlying chemical kinetics. The detailed reaction mechanism described below is developed by Zheng et al. [10,16]. Discussions about the mechanism development process are worthy. More details about the mechanism involved in the catalytic oxidation process of syngas over platinum can be found in the original works $[10,16]$. The areas where changes to the mechanism of the reaction are made based on the kinetic data available from the literature are described below.

Both adsorption-desorption of carbon monoxide and oxidation of the adsorbed carbon monoxide are the primary factors that affect the chemistry during the low-temperature catalytic oxidation of carbon monoxide over platinum [16]. Consequently, newly kinetic data available from the literature are incorporated into the surface reaction mechanism. Specifically, kinetic parameters for these important reaction steps (R8, R15, and R21 shown in Table 1) in the low-temperature catalytic oxidation process, as well as the oxidation reaction of the adsorbed atomic hydrogen with the adsorbed atomic oxygen (R9) and its reverse reaction (R10), are firstly updated in the mechanism developed by Deutschmann et al. [63], on the basis of the latest literature data obtained from Salomons et al. [36], as well as Koop and Deutschmann [64].

On the other hand, it has been found that the $\mathrm{COOH}^{*}$ chemistry is crucial and needs to be accounted for [6]. Consequently, additional mechanistic steps involving the adsorbed formate $\left(\mathrm{HCOO}^{*}\right)[64]$ are added to the basic mechanism to treat the intermediate product and subsequent reactions. Note that such minor modifications are necessary, as discussed in detail in the previous works 
of Zheng et al. $[10,16]$. The updated mechanism of the low-temperature catalytic oxidation reaction is listed in Table 1. The additional mechanistic steps (R15-R22) involving the adsorbed intermediate formate are taken from the previous work of Koop and Deutschmann [64]. The resulting mechanism consists of nine species on the surface of the catalyst and eight species in the gas phase involved in twenty-seven elementary reactions. Please refer to the original works of Zheng et al. [10,16] for further information about the development of the kinetic mechanism for the syngas catalytic oxidation process, and the interaction between carbon monoxide and hydrogen oxidation over platinum occurring at low temperatures.

It is important to acknowledge the major limitations in the mechanism of the low-temperature catalytic oxidation reaction. Coking kinetics are not significant over platinum [72], and thus are not included in the mechanism. This chemistry, however, may be important for other catalysts, especially at low temperatures. Additionally, the mechanism does not take into account all the possible species and reaction steps in the system. Despite the limitations outlined above, this mechanism can be used to understand the combined oxidation reaction, with which reactor design and process optimization could be carried out.

Table 1. Updated surface reaction mechanism for the low-temperature catalytic oxidation of hydrogen and carbon monoxide over platinum.

\begin{tabular}{|c|c|c|c|c|c|c|}
\hline & Reactions & $s_{c}$ & $A$ & $n$ & $E a$ & References \\
\hline \multicolumn{7}{|c|}{ Adsorption } \\
\hline R1 & $\mathrm{H}_{2}+2^{*} \Rightarrow 2 \mathrm{H}^{*}$ & 0.046 & & & & [63] \\
\hline $\mathrm{R} 2$ & $\mathrm{H}^{2}{ }^{*} \Rightarrow \mathrm{H}^{*}$ & 1.00 & & & & [63] \\
\hline $\mathrm{R} 3$ & $\mathrm{O}_{2}+2^{*} \Rightarrow 2 \mathrm{O}^{*}$ & & $1.80 \times 10^{+21}$ & -0.5 & 0 & [63] \\
\hline $\mathrm{R} 4$ & $\mathrm{O}_{2}+2^{*} \Rightarrow 2 \mathrm{O}^{*}$ & 0.023 & & & & [63] \\
\hline R5 & $\mathrm{O}+{ }^{*} \Rightarrow \mathrm{O}^{*}$ & 1.00 & & & & [63] \\
\hline R6 & $\mathrm{H}_{2} \mathrm{O}+{ }^{*} \Rightarrow \mathrm{H}_{2} \mathrm{O}^{*}$ & 0.75 & & & & [63] \\
\hline R7 & $\mathrm{OH}+{ }^{*} \Rightarrow \mathrm{OH}^{*}$ & 1.00 & & & & [63] \\
\hline $\mathrm{R} 8$ & $\mathrm{CO}+{ }^{*} \Rightarrow \mathrm{CO}^{*}$ & 0.84 & & & & {$[36,63,64]$} \\
\hline \multicolumn{7}{|c|}{ Surface reactions } \\
\hline $\mathrm{R} 9$ & $\mathrm{H}^{*}+\mathrm{O}^{*} \Rightarrow \mathrm{OH}^{*}+*$ & & $3.70 \times 10^{20}$ & 0 & 70.50 & {$[36,63,64]$} \\
\hline R10 & $\mathrm{OH}^{*}+* \Rightarrow \mathrm{H}^{*}+\mathrm{O}^{*}$ & & $1.00 \times 10^{20}$ & 0 & 130.69 & {$[36,63,64]$} \\
\hline R11 & $\mathrm{H}^{*}+\mathrm{OH}^{*} \Leftrightarrow \mathrm{H}_{2} \mathrm{O}^{*}+*$ & & $3.70 \times 10^{+21}$ & 0 & 17.4 & [63] \\
\hline R12 & $\mathrm{OH}^{*}+\mathrm{OH}^{*} \Leftrightarrow \mathrm{H}_{2} \mathrm{O}^{*}+\mathrm{O}^{*}$ & & $3.70 \times 10^{+21}$ & 0 & 48.2 & [63] \\
\hline R13 & $\mathrm{C}^{*}+\mathrm{O}^{*} \Rightarrow \mathrm{CO}^{*}+*$ & & $3.70 \times 10^{+21}$ & 0 & 62.8 & [63] \\
\hline R14 & $\mathrm{CO}^{*}+* \Rightarrow \mathrm{C}^{*}+\mathrm{O}^{*}$ & & $1.00 \times 10^{+18}$ & 0 & 184.0 & [63] \\
\hline R15 & $\mathrm{CO}^{*}+\mathrm{O}^{*} \Rightarrow \mathrm{CO}_{2}^{*}+^{*}$ & & $3.70 \times 10^{20}$ & 0 & $108.00-33.00 \Theta_{\mathrm{CO}^{*}}$ & {$[36,64]$} \\
\hline R16 & $\mathrm{CO}^{*}+\mathrm{OH}^{*} \Rightarrow \mathrm{HCOO}^{*}+^{*}$ & & $3.70 \times 10^{21}$ & 0 & 94.20 & {$[64]$} \\
\hline R17 & $\mathrm{HCOO}^{*}+{ }^{*} \Rightarrow \mathrm{OH}^{*}+\mathrm{CO}^{*}$ & & $1.33 \times 10^{21}$ & 0 & 0.87 & [64] \\
\hline R18 & $\mathrm{HCOO}^{*}+\mathrm{O}^{*} \Rightarrow \mathrm{OH}^{*}+\mathrm{CO}_{2}^{*}$ & & $3.70 \times 10^{21}$ & 0 & 0 & [64] \\
\hline R19 & $\mathrm{OH}^{*}+\mathrm{CO}_{2}^{*} \Rightarrow \mathrm{HCOO}^{*}+\mathrm{O}^{*}$ & & $2.79 \times 10^{21}$ & 0 & 151.05 & [64] \\
\hline R20 & $\mathrm{HCOO}^{*}+{ }^{*} \Rightarrow \mathrm{CO}_{2}^{*}+\mathrm{H}^{*}$ & & $3.70 \times 10^{21}$ & 0 & 0 & [64] \\
\hline \multicolumn{7}{|c|}{ Desorption } \\
\hline R21 & $\mathrm{CO}^{*} \Rightarrow \mathrm{CO}+^{*}$ & & $2.13 \times 10^{13}$ & 0 & $136.19-33.00 \Theta_{\mathrm{CO}^{*}}$ & {$[36,64]$} \\
\hline R22 & $\mathrm{CO}_{2}{ }^{*}+\mathrm{H}^{*} \Rightarrow \mathrm{HCOO}^{*}+*$ & & $2.79 \times 10^{21}$ & 0 & 90.05 & [64] \\
\hline R23 & $2 \mathrm{H}(\mathrm{s}) \Rightarrow \mathrm{H}_{2}+2 \mathrm{Pt}(\mathrm{s})$ & & $3.70 \times 10^{+21}$ & 0 & $67.4-6.0 \Theta_{\mathrm{H}^{*}}$ & [63] \\
\hline R24 & $2 \mathrm{O}^{*} \Rightarrow \mathrm{O}_{2}+2^{*}$ & & $3.70 \times 10^{+21}$ & 0 & $213.2-60 \Theta_{\mathrm{O}^{*}}$ & [63] \\
\hline R25 & $\mathrm{H}_{2} \mathrm{O}^{*} \Rightarrow \mathrm{H}_{2} \mathrm{O}+*$ & & $1.0 \times 10^{+13}$ & 0 & 40.3 & [63] \\
\hline R26 & $\mathrm{OH}^{*} \Rightarrow \mathrm{OH}+*$ & & $1.0 \times 10^{+13}$ & 0 & 192.8 & [63] \\
\hline R27 & $\mathrm{CO}_{2}^{*} \Rightarrow \mathrm{CO}_{2}{ }^{*}$ & & $1.00 \times 10^{+13}$ & 0 & 20.5 & [63] \\
\hline
\end{tabular}

The detailed reaction mechanism shown above is developed by Zheng et al. [10,16]. The basic mechanism is taken from Deutschmann et al. [63], and the reaction steps (R8-R10, R15, and R21) are updated with kinetic data obtained from Salomons et al. [36], as well as Koop and Deutschmann [64], as reported in the previous works of Zheng et al. [10,16]. The asterisk $\left(^{*}\right)$ denotes an empty site or an adsorbed species. The additional reaction steps (R15-R22) involving the adsorbed intermediate formate $\left(\mathrm{HCOO}^{*}\right)$ are taken from Koop and Deutschmann [64]. The reaction step R1 is given in terms 
of a sticking coefficient and is one order with respect to the empty site. The reaction step R8 is two order with respect to the empty site. The units of pre-exponential factor $A$, which is an empirical relationship between the temperature and rate coefficient, are given in terms of $(\mathrm{mol}, \mathrm{cm}, \mathrm{s})$. The units of activation energy $E a$ are in $(\mathrm{kJ} / \mathrm{mol})$. The density of sites, $\Gamma$, is assumed to be $2.7 \times 10^{-9} \mathrm{~mol} / \mathrm{cm}^{2}$. Reaction steps R3 and R4 represent alternative competive pathways. The rate coefficient of the forward reaction $k$ can be expressed as follows:

$$
k_{f_{k}}=A_{k} T^{\beta^{\prime}}{ }_{k} \exp \left[\frac{-E a_{k}}{R T}\right] \prod_{i=1}^{K_{s}} \Theta_{i}^{\mu_{i k}} \exp \left[\frac{\varepsilon_{i_{k}} \Theta_{i}}{R T}\right] .
$$

\subsection{Numerical Validation}

The experimental data and numerical results reported in the literature [10] are utilized to verify the numerical model implemented in this paper. A syngas-air mixture with a global equivalence ratio of 0.13 is considered, corresponding to Case 2 of the experimental data reported by Zheng et al. [10]. The molar ratio of carbon monoxide to hydrogen at the inlet is 3.25 , and the inlet pressure is $0.5 \mathrm{MPa}$. The reactor consists of two parallel ceramic plates that are $300.0 \mathrm{~mm}$ long, $110.0 \mathrm{~mm}$ wide, $9.0 \mathrm{~mm}$ thick, and a distance of $7.0 \mathrm{~mm}$ apart. The gas temperature at the inlet is $305 \mathrm{~K}$. The temperatures measured on the walls are taken as the boundary condition of the energy equation at the fluid-solid interfaces. More details are available in the previous work of Zheng et al. [10]. The entire reactor geometry is modeled here due to the lack of symmetry, and a uniform mesh consisting of 28,000 nodes in total is used for this reactor dimension.

The transverse profiles of carbon monoxide and hydrogen mole fractions at different streamwise positions predicted by the present work are compared to the experimental data and numerical results in Figure 5. There is a slight difference in species mole fractions by a maximum of approximately $7.6 \%$, which is well within the range of measurement uncertainties. Overall, the numerical results of the present work are in good agreement with the experimental data.

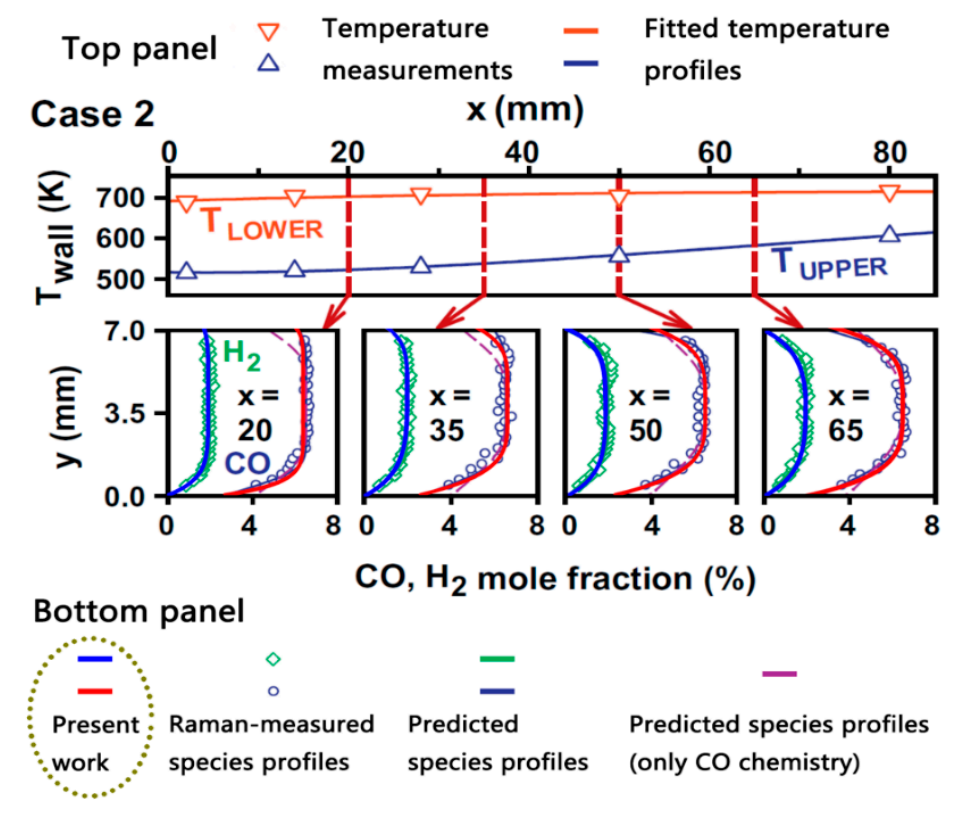

Figure 5. Transverse profiles of carbon monoxide and hydrogen mole fractions at the streamwise positions indicated, compared to the experimental data and numerical results reported in the literature [10]. The top panel shows the temperature measurements and the fitted temperature profiles. The bottom panel shows the numerical predictions of the present work, as well as the experimental data and numerical results reported in the literature [10]. 


\subsection{Reactor Modeling}

As mentioned earlier in this paper, the gas-phase chemistry is included in the numerical model by using the mechanism proposed by Li et al. [65], improved by Burke et al. [66], in order to account for the homogeneous reactions occurring in the oxidation system. Mass-transfer limitations in the reactor are also accounted for. Computational fluid dynamics simulations are carried out for various cases under the inlet conditions given in Table 2. The pressure is $0.6 \mathrm{MPa}$ at the inlet. The fuel is syngas with a varying hydrogen and carbon monoxide composition, and the global equivalence ratio is within the range from 0.1 to 0.167 . The concentration of oxygen is $30.0 \%$ by volume in the total mixture due to oxygen enrichment.

Table 2. Inlet conditions that are used for computations.

\begin{tabular}{lcccccc}
\hline \multicolumn{1}{c}{ Parameter } & Variable & Case A & Case B & Case C & Case D & Case E \\
\hline Equivalence ratio & $\varphi$ & 0.167 & 0.150 & 0.133 & 0.117 & 0.1 \\
Volume fraction of hydrogen & $\beta_{\mathrm{H}_{2}}(\%)$ & 4.0 & 3.0 & 2.0 & 1.0 & 0 \\
Volume fraction of carbon monoxide & $\beta_{\mathrm{CO}}(\%)$ & 6.0 & 6.0 & 6.0 & 6.0 & 6.0 \\
Volume fraction of oxygen & $\beta_{\mathrm{O}_{2}}(\%)$ & 30.0 & 30.0 & 30.0 & 30.0 & 30.0 \\
Volume fraction of nitrogen & $\beta_{\mathrm{N}_{2}}(\%)$ & 60.0 & 61.0 & 62.0 & 63.0 & 64.0 \\
Inlet temperature & $T_{\text {in }}(\mathrm{K})$ & 300 & 300 & 300 & 300 & 300 \\
Inlet velocity & $u_{\text {in }}(\mathrm{m} / \mathrm{s})$ & 2.0 & 2.0 & 2.0 & 2.0 & 2.0 \\
Inlet pressure & $p_{\text {in }}(\mathrm{MPa})$ & 0.6 & 0.6 & 0.6 & 0.6 & 0.6 \\
\hline
\end{tabular}

Numerical simulations are performed using the updated oxidation mechanism described above to determine the effect of homogeneous reactions occurring in the system. Preliminary simulations indicate that the presence of homogeneous reactions has little effect on the reactor performance. Homogeneous reactions are insignificant in the temperature range examined here, and the complete results coincide with those obtained for the case where only heterogeneous chemistry is allowed. The initiation of homogeneous reactions is impossible under the conditions studied here, and thus the contribution from this pathway is negligible. The reactor is then modeled by taking only surface chemistry into account.

Based on the model developed in this paper, it is possible to accurately predict the depletion of hydrogen and carbon monoxide on the surface of the catalyst, and the formation of products along the reactor, thus providing valuable information about the low-temperature catalytic oxidation process and the kinetic interplay between carbon monoxide and hydrogen. The contour plot of the temperature and hydrogen and water mole fractions for Case A is shown in Figure 6. Diffusion of the reactants from the bulk fluid to the surface of the catalyst on which they are adsorbed can be seen. The oxidation reaction of syngas takes place on the surface of the catalyst, after which the products formed desorb from the surface, and then diffuse into the bulk fluid. Heat is generated by the oxidation reaction on the surface of the catalyst, thus heating up both the wall and the fluid. The primary mechanism of heat recirculation within the system is the conduction of the heat generated by the oxidation reaction through the walls $[13,73]$.

Despite the small scale involved in the oxidation system, significant gradients in the concentration of the species in the gas phase, as well as the temperature of the fluid, can be found in the transverse direction, as shown in Figure 6. Additionally, Figure 6 also shows that the diffusion of both heat and mass cannot be ignored within the fluid in the streamwise direction. It is therefore necessary to use a two-dimensional numerical model in order to provide an accurate description of the low-temperature catalytic oxidation process. Despite the significant concentration and temperature gradients in the fluid in the transverse direction, no significant gradient in temperature can be found within the walls in all the cases examined here due to the high wall thermal conductivity used, making nearly isothermal wall conditions possible. It is therefore possible to decouple the kinetic effects from thermal effects, which is very important when investigating the intrinsic kinetics of the oxidation reaction within the system. 


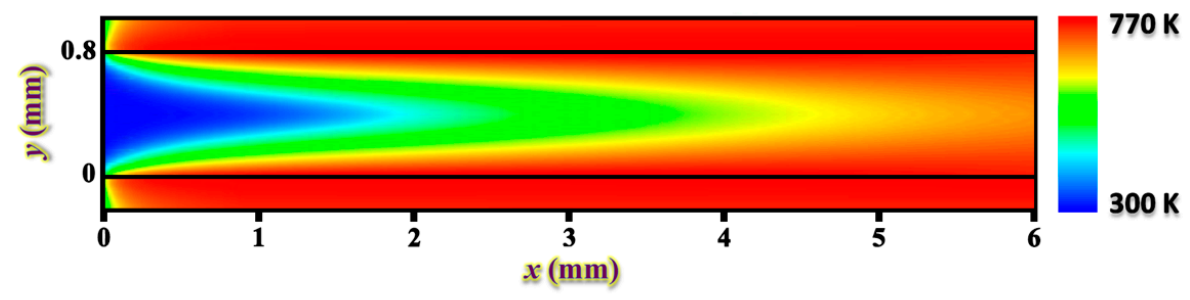

Temperature

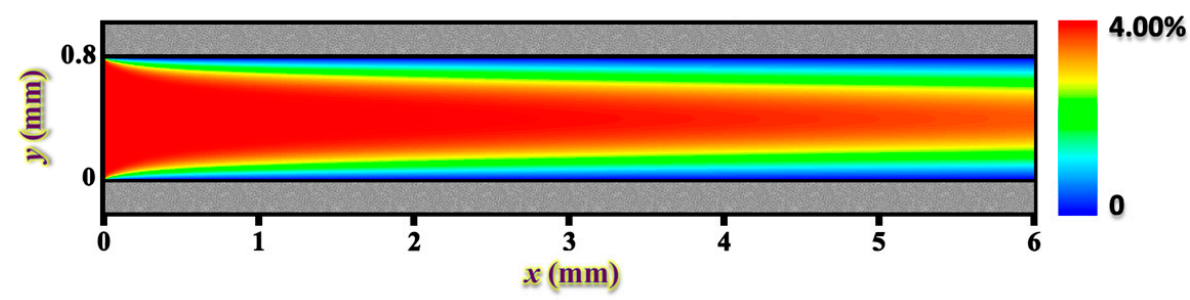

Hydrogen mole fraction

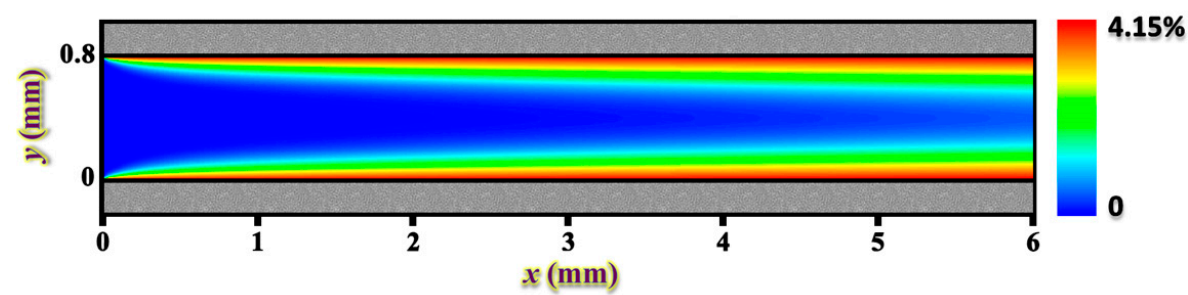

Water mole fraction

Figure 6. Contour plot of the temperature and hydrogen and water mole fractions for Case A shown in Table 2.

The effect of varying the hydrogen concentrations on the low-temperature oxidation of carbon monoxide over platinum is examined here. The typical profiles of species, temperature, and conversion are presented in Figures 7 and 8. The transverse profiles of carbon monoxide and hydrogen concentrations are shown in Figure 7 for Cases A-D, and the wall temperature and conversion profiles are shown in Figure 8. These cases have the same amount of carbon monoxide, while decreasing the hydrogen molar fraction from $4.0 \%$ in Case A to $1.0 \%$ in Case D, as shown in Table 2. Figure 7 shows that the hydrogen concentration drops to almost zero in the vicinity of the catalytic surface. The bending of species profiles in the near-surface region suggests that the low-temperature oxidation of hydrogen is limited by mass transfer under the conditions studied here. In contrast, the low-temperature oxidation of carbon monoxide over platinum is considered to be finite-rate chemistry, i.e., both kinetically and transport controlled. The range of surface temperature from 500 to $770 \mathrm{~K}$ examined here is of particular relevance to catalytic combustion gas turbine applications. Furthermore, the rates of mass transport from the bulk fluid to the surface of the catalyst are almost similar in all the cases examined here. Consequently, the hydrogen conversion is roughly the same, as confirmed by the profiles of hydrogen conversion shown in Figure 8. In contrast, the conversion of carbon monoxide is determined by both transport and kinetics during the combined oxidation process, since it changes from approximately $10.8 \%$ at the exit of the reactor in Case A to approximately $8.0 \%$ in Case D. This is due to the decreased wall temperature from approximately $690-770 \mathrm{~K}$ in Case A to approximately $600-680 \mathrm{~K}$ in Case D (as shown in Figure 8), and to the decreased amount of hydrogen in the feed. The latter is of particular interest for the present investigation. 

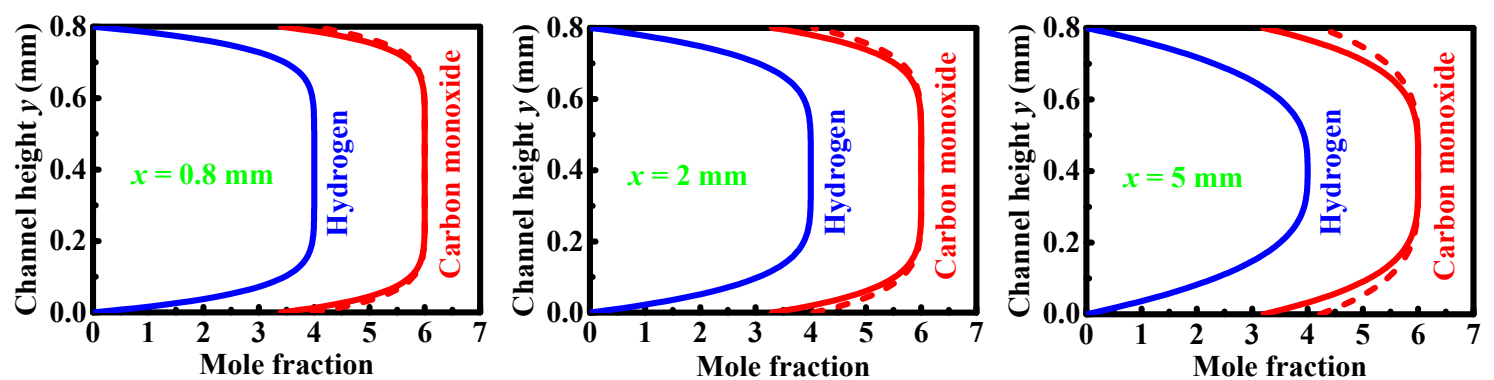

(a) Case A
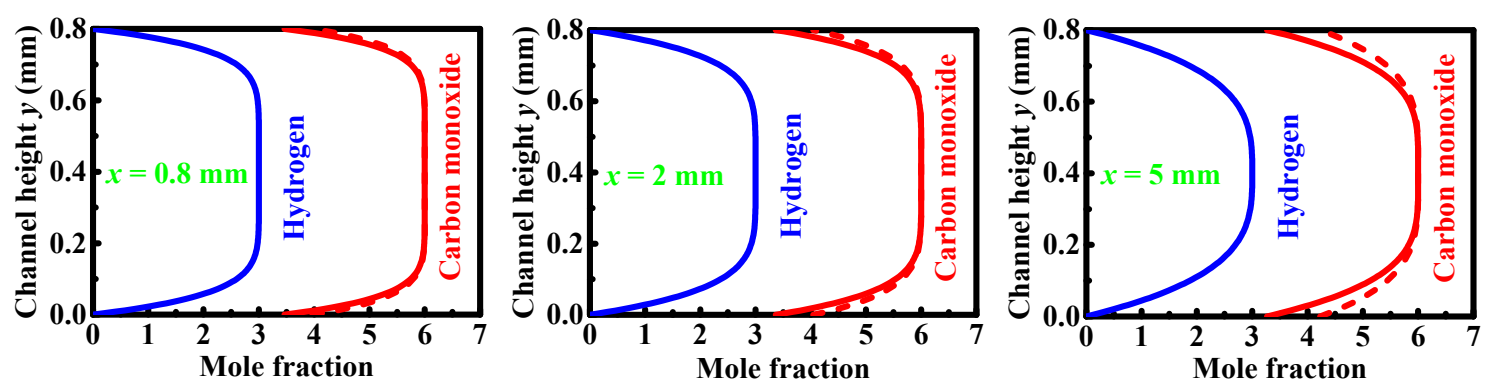

(b) Case B
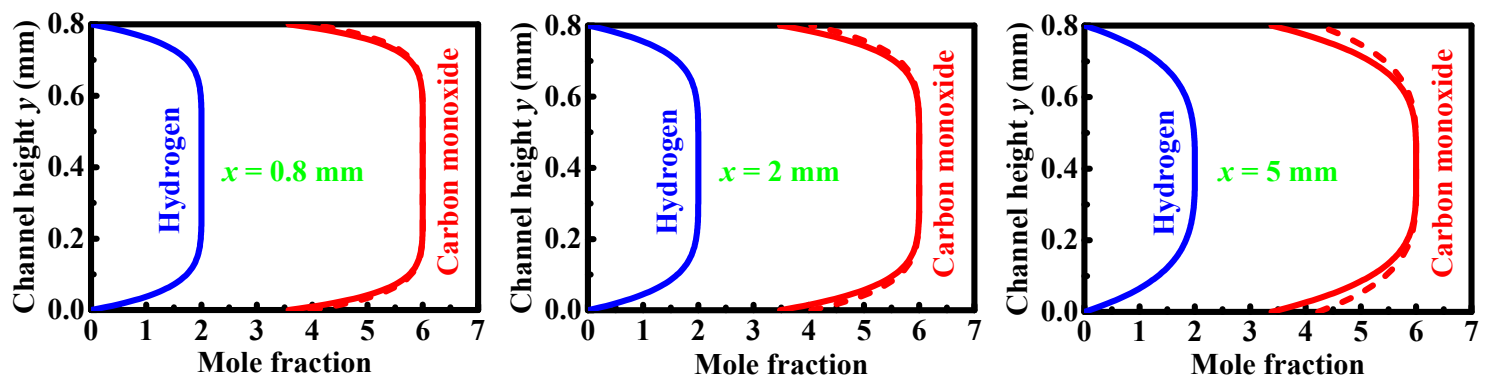

(c) Case C
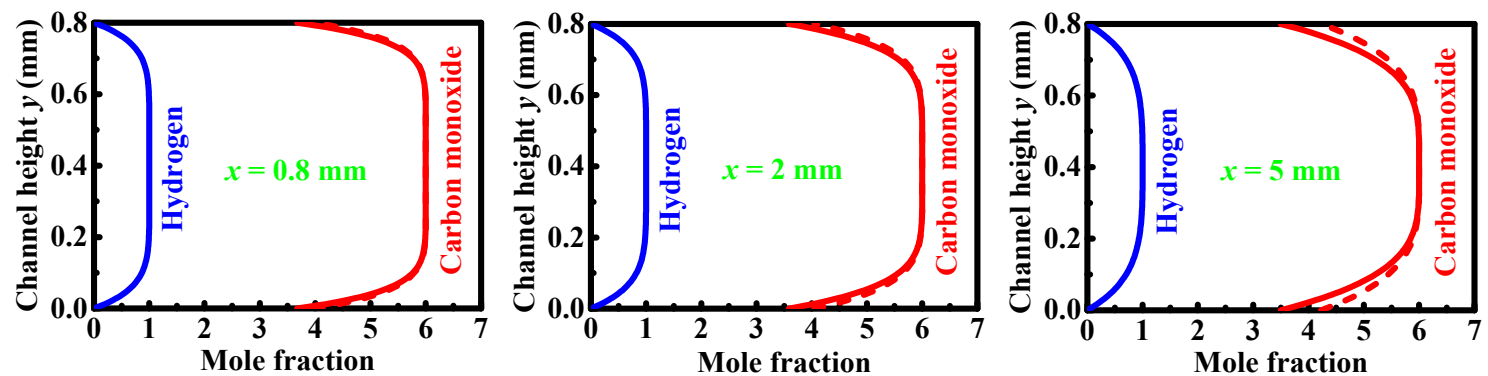

(d) Case D

Figure 7. Transverse profiles of carbon monoxide and hydrogen mole fractions for Cases A-D shown in Table 2 at the axial positions indicated. Hereafter, solid-lines and dashed-lines represent the results obtained from the improved mechanism herein and from the mechanism without any hydrogen-involved reactions, respectively.

\subsection{Effect of Hydrogen Addition through a Direct Pathway}

In an attempt to examine the kinetic effect of the addition of hydrogen in the feed, numerical simulations are carried out in the case where molecular hydrogen acts purely as a chemically inert species. In this context, all the elementary reactions that are relevant to molecular hydrogen are removed. Numerical simulations are repeated for Cases A-D, and subsequently compare the results 
with those obtained from the full reaction mechanism, as shown in Figures 7 and 8 . The results indicate that hydrogen has a promoting effect on the catalytic oxidation of carbon monoxide for all the cases studied here. The promoting effect becomes more pronounced as the hydrogen content increases. The kinetic effect of the addition of hydrogen in the feed probably arises from two different chemical routes. One is the direct pathway via the elementary steps involving the adsorbed formate species on the surface of catalyst, providing a feasible chemical route for the combined oxidation process. This reaction pathway is analyzed by performing the numerical simulations after eliminating all the elementary reactions that are relevant to the surface formate species. It is shown that there is no difference between the results obtained from this reduced reaction mechanism and from the full reaction mechanism. This direct pathway is of no great importance in the mechanism of the low-temperature catalytic oxidation reaction of syngas. This is because there is an extremely low branching ratio between the rate of formation of the intermediate formate on the surface of the catalyst (R16 in Table 1) and that of oxidation of the adsorbed carbon monoxide with the adsorbed atomic oxygen (R15 in Table 1). The two mechanistic steps have a similar reaction rate constant but, under the conditions studied here, the concentration of the surface hydroxyl group is at least two orders of magnitude lower than that of the adsorbed atomic oxygen.

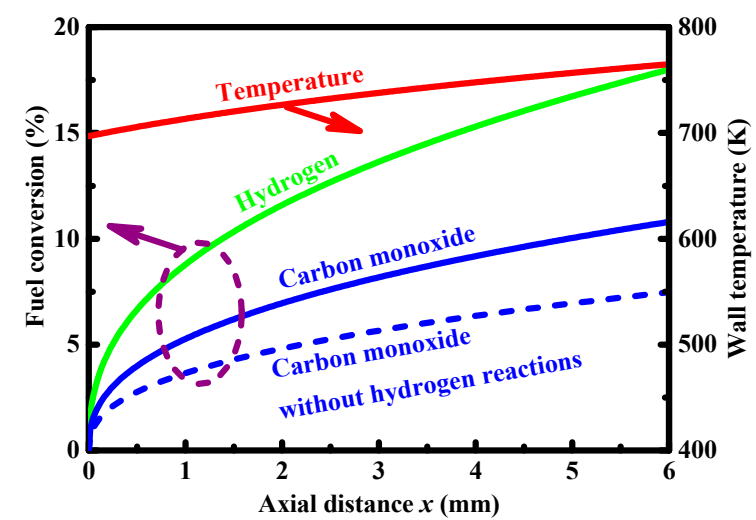

(a) Case A

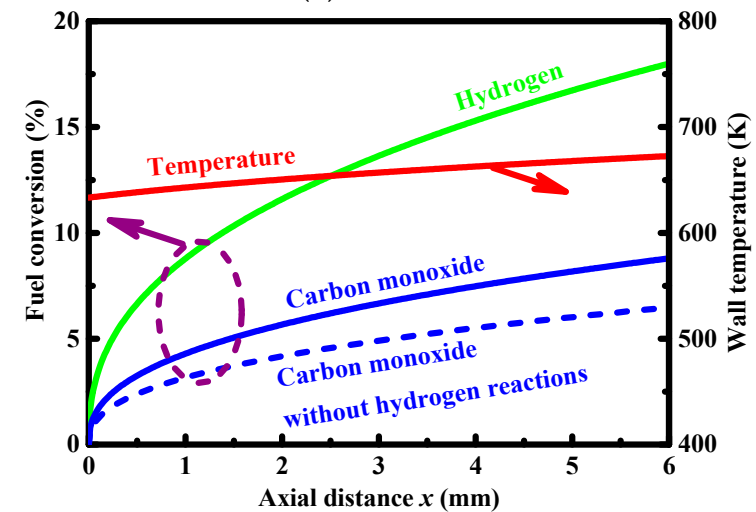

(c) Case C

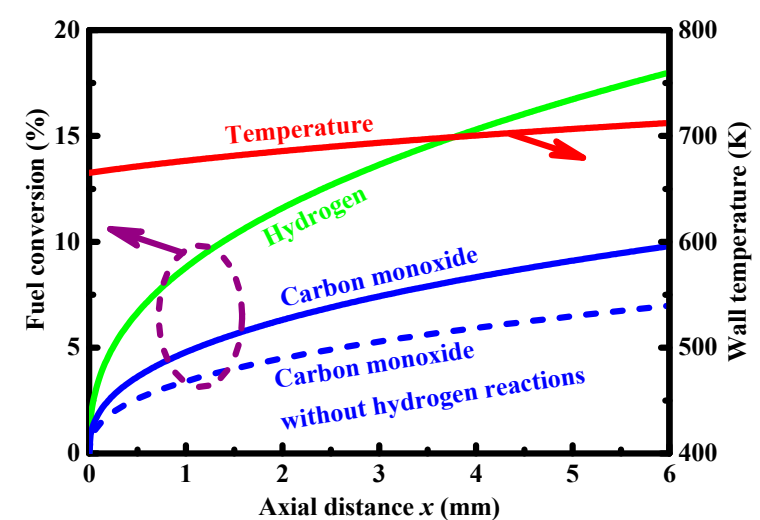

(b) Case B

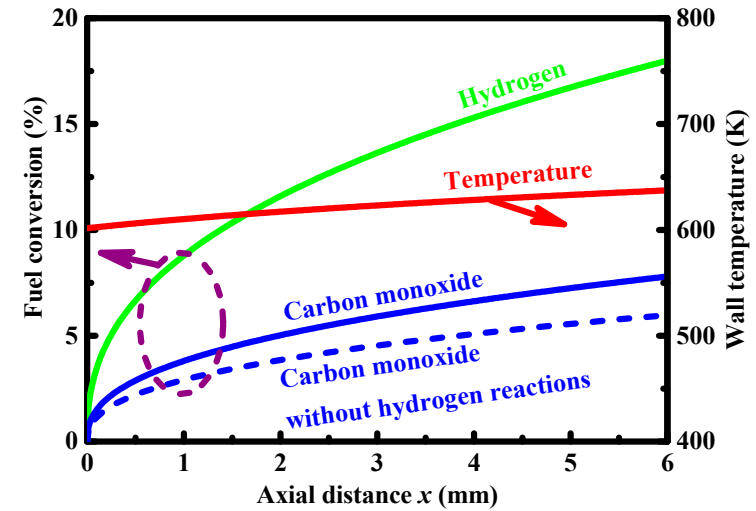

(d) Case D

Figure 8. Wall temperature and conversion profiles for Cases A-D shown in Table 2.

\subsection{Effect of Hydrogen Addition through an Indirect Pathway}

To gain a better understanding of the underlying mechanism, the indirect pathway through surface coverage is subsequently examined here since the contribution from the direct pathway via the intermediate formate is minor, as discussed above. The rate of carbon monoxide consumption depends strongly on the rate of adsorption of carbon monoxide from the bulk fluid onto the surface 
of the catalyst, and the latter is a function of the available empty site. Hereafter, the term "empty site" refers to the unit of unoccupied surface, i.e., the active surface sites available for adsorption.

Numerical simulations are performed, and the results obtained indicate that hydrogen reactions result in an increase in the number of active surface sites available for adsorption, which has a beneficial effect on the low-temperature oxidation of carbon monoxide over platinum. The possible sequence of mechanistic steps such as the adsorption, surface reactions, and desorption in the mechanism of the oxidation reaction is analyzed as follows. The molecular hydrogen in the gas phase adsorbs on the surface of the catalyst to produce the adsorbed atomic hydrogen (R1 in Table 1), followed by oxidation with the adsorbed atomic oxygen to form the surface hydroxyl group (R9) and further mechanistic steps to form the adsorbed molecular water (R11 and R12), which desorbs from the surface of the catalyst into the gas phase and finally forms a gaseous water molecule (R25). This chemical route heavily consumes the adsorbed atomic oxygen, and thus there are a large number of active surface sites available for adsorption. To further understand the effect of the amount of hydrogen in the feed on the low-temperature oxidation of carbon monoxide over platinum, a comparison of empty sites is made between different concentrations of hydrogen in the feed. The results obtained for the fractional coverage of empty sites are shown in Figure 9 for Cases A and D, since the highest and the lowest surface temperatures are achieved for them, respectively. The fractional coverage of major surface species is also shown in Figure 9 for both Cases. The fractional coverage of empty sites increases with an increasing amount of hydrogen in the feed. A greater amount of hydrogen makes the empty sites more available. Recent experiments have demonstrated that the catalyst temperature can also affect the fractional coverage of empty sites, and lower temperatures render this effect more pronounced, making the empty sites less available [10].

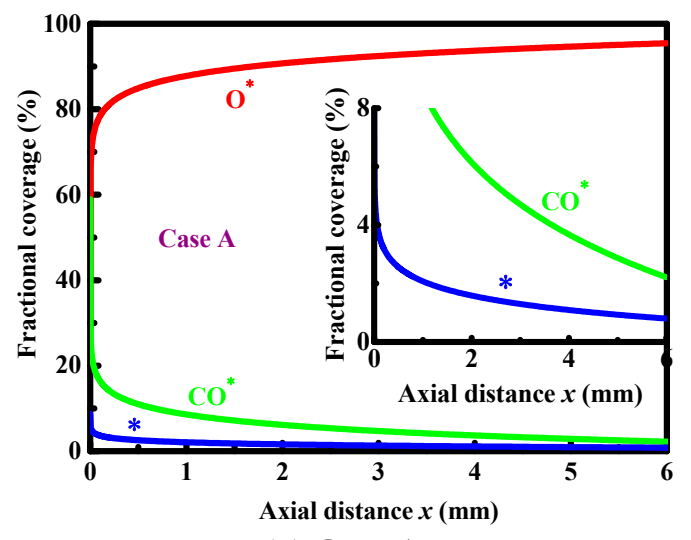

(a) Case A

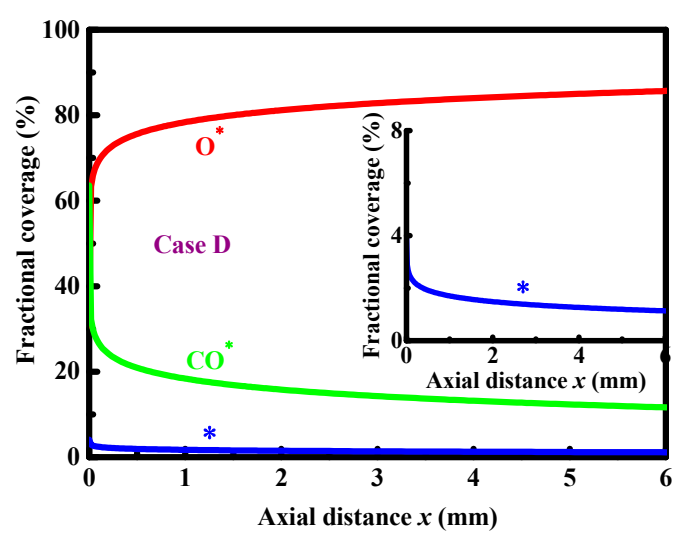

(b) Case D

Figure 9. Fractional coverage of empty sites and major species for Cases A and D, obtained from the improved mechanism herein.

\subsection{Critical Temperature}

The present work focuses on the temperature range from 500 to $770 \mathrm{~K}$, which is relevant to the catalyst inlet temperature encountered in catalytic combustion gas turbine systems [10]. The chemistry during the catalytic oxidation of syngas in this temperature range is of particular interest to real operating conditions encountered in catalytic combustion gas turbine systems [10]. In this situation, hydrogen has a beneficial effect on the low-temperature oxidation of carbon monoxide over platinum, as discussed earlier. This range of temperature is usually applied to partially light-off of carbon monoxide, as well as to fully light-off of hydrogen. Note that the light-off temperature refers to the temperature at which significant oxidation reactions occur [74]. These situations are usually encountered in the normal operating mode in both catalytic combustion gas turbine and micro-turbine systems, since the catalyst would attain the discharge temperature of the compressor as low as $600 \mathrm{~K}$. 
It is important to note that a transition temperature of $550 \mathrm{~K}$ has been found by Zheng et al. [10,16], below which the presence of hydrogen has an inhibiting effect on the catalytic oxidation of carbon monoxide over platinum under the conditions set out therein. The mechanism responsible for this inhibiting effect has also been identified $[10,16]$.

In this section, the surfaces of the two parallel plates are assumed to be isothermal, and the wall temperature is the controlled parameter. Computational fluid dynamics simulations are performed for Cases $\mathrm{A}$ and $\mathrm{D}$ at different wall temperatures. The results obtained indicate that hydrogen has an inhibiting effect on the oxidation reaction of carbon monoxide over platinum, but only at temperatures below $520 \mathrm{~K}$. An example to demonstrate this inhibiting effect is illustrated in Figure 10, which presents a test result obtained from the profiles of carbon monoxide and hydrogen concentrations for Cases A and $\mathrm{D}$ at a wall temperature of $500 \mathrm{~K}$. The results obtained indicate that in the transverse direction, there is no significant gradient in the concentration of the species in the vicinity of the catalytic surface. Neither hydrogen nor carbon monoxide is light-off, leading to very low activity of the catalyst for the combined oxidation reaction. Note that catalyst inlet temperatures below $520 \mathrm{~K}$ are relevant to the part-load and idling operation in gas turbine systems [10]. A comparison is made between the results obtained for Cases A and D at wall temperatures above $600 \mathrm{~K}$, presented in Figure 7, and at a wall temperature of $500 \mathrm{~K}$, presented in Figure 10. There is a role transition of hydrogen from promotion to inhibition. Note that the critical point, $520 \mathrm{~K}$, is close to the light-off temperature for the oxidation reaction of carbon monoxide over platinum under the conditions examined here $[8,36,37,70]$. To further understand the kinetic interplay between carbon monoxide and hydrogen during their combined oxidation process, computational fluid dynamics simulations are performed for the case at temperatures below $500 \mathrm{~K}$. The results obtained indicate that the initiation of the oxidation reaction of carbon monoxide over platinum is almost impossible at these low temperatures, irrespective of the presence of hydrogen.
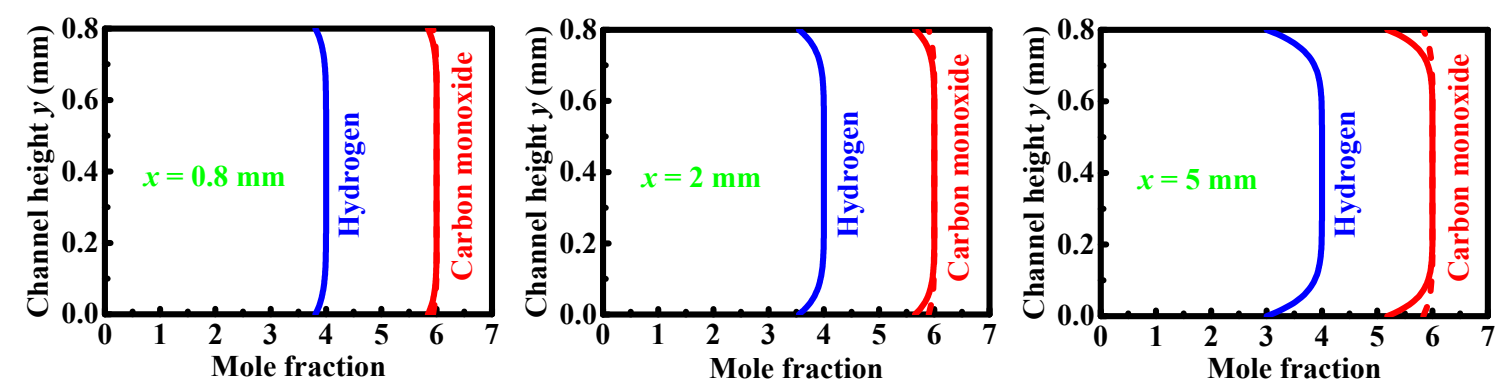

(a) Case A
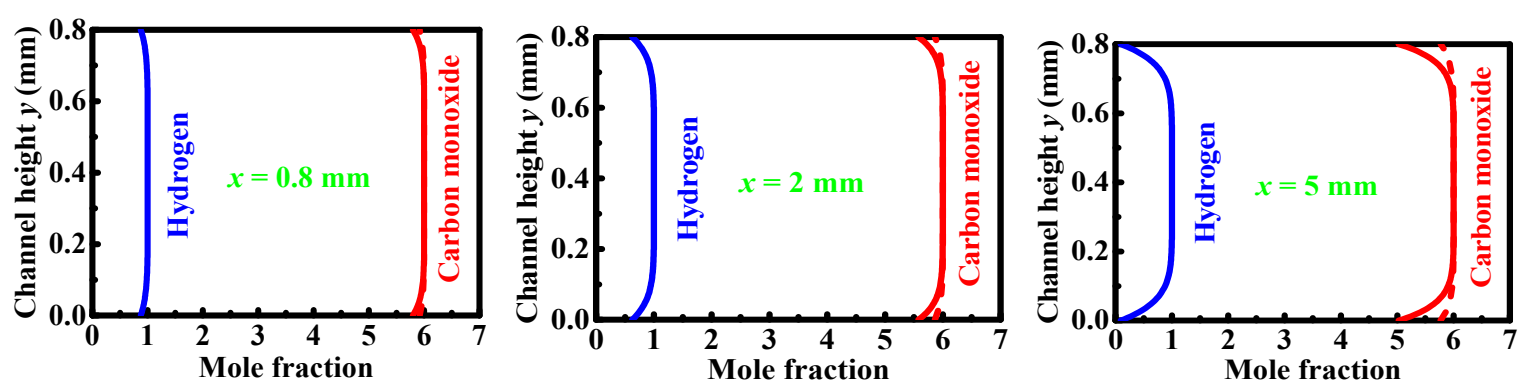

(b) Case D

Figure 10. Transverse profiles of carbon monoxide and hydrogen mole fractions for Cases $A$ and $D$ at a constant surface temperature of $500 \mathrm{~K}$. 


\subsection{Effect of Mass Transfer}

Although there is a significant reduction in the mass-transfer resistances under the present conditions, the content of hydrogen in the vicinity of the catalytic surface is still very low, as shown in Figure 6. There are two main types of potential mass-transfer limitation in the reactor. The first type is the diffusional limitation in the catalyst washcoat in the presence of a fast oxidation reaction. While the washcoat considered in the present work is very thin, diffusional limitation is significant under the conditions studied here, which is consistent with the results obtained by Rodríguez and L.E. Cadús [75] and Daele et al. [76]. The second type is the transverse diffusional limitation of reactants from the bulk fluid to the external surface of the catalyst washcoat. Molecular diffusion is the main mechanism of transverse mass transfer in the reactor, since the flow is laminar.

The effect of hydrogen addition on the low-temperature oxidation of carbon monoxide over platinum becomes more important in the absence of mass-transfer limitations, as discussed below. Numerical simulations are performed using a simplified low-dimensional model, a surface perfectly stirred reactor, for a constant set of operating conditions and the reactant compositions shown in Table 2. Both heat transfer phenomena and diffusion limitations are negligible for these computations, and the surface perfectly stirred reactor is considered to be isothermal. The results obtained indicate that the chemically inhibiting effect of hydrogen addition on the low-temperature oxidation of carbon monoxide over platinum in the surface perfectly stirred reactor is demonstrated at higher temperatures $(540-560 \mathrm{~K})$. This is because there is a competitive adsorption of oxygen and hydrogen on the surface of the catalyst, i.e., the two components compete for the same active sites on the catalyst. There is a large amount of hydrogen available in the vicinity of the catalytic surface, thus effectively competing with oxygen for adsorption sites. This results in lower surface coverage of the adsorbed atomic oxygen, which is the deficient surface species determining the oxidation process of the adsorbed carbon monoxide.

\subsection{Analysis of the Surface Reaction Mechanism}

To gain a better understanding of the surface reaction mechanism, the degree of rate control, as suggested by Campbell [77,78], for all the elementary steps in the mechanism, is computed in the absence of mass-transfer limitations to identify the rate-determining step or rate-limiting steps. The degree of rate control is computed in the presence and absence of hydrogen in the feed under light-off conditions, respectively. The results obtained indicate that there are two rate-limiting steps in the absence of hydrogen: the adsorption of oxygen on the surface of the catalyst, as well as the surface oxidation reaction of the adsorbed carbon monoxide with the adsorbed atomic oxygen. In contrast, the adsorbed atomic oxygen on the surface of the catalyst is consumed rapidly in the presence of hydrogen by the additional intermediate formate pathway. Consequently, the adsorption of oxygen on the surface of the catalyst becomes the rate-determining step.

To decouple kinetic effects from thermal effects as much as possible, the surfaces of the two parallel plates are assumed to be isothermal, and the wall temperature is the controlled parameter. Numerical simulations are performed in the absence of mass-transfer limitations under isothermal surface conditions. In this context, the energy equation in the wall is not accounted for. The results obtained for Cases D and E are summarized in Figure 11, where the fractional coverage of major surface species is plotted as a function of wall temperature in the presence and absence of hydrogen in the feed, respectively. The light-off temperature for the oxidation reaction of carbon monoxide over platinum is plotted as a dashed vertical line for each of the Cases. 


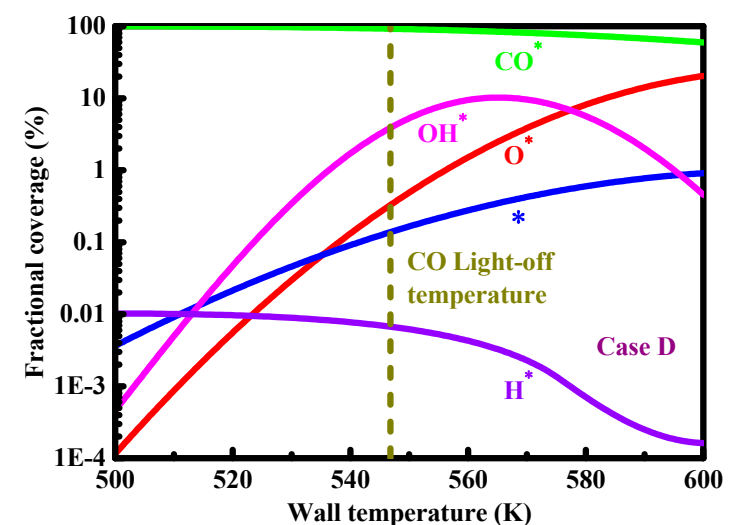

(a) Case D

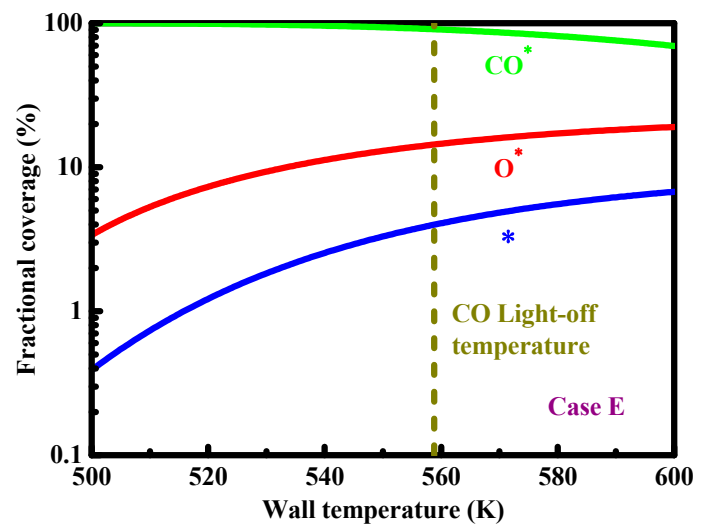

(b) Case E

Figure 11. Fractional coverage of major surface species as a function of wall temperature for Cases D and $\mathrm{E}$ shown in Table 2. Case D represents syngas mixtures with hydrogen, whereas Case E represents syngas mixtures without hydrogen.

Figure 11 shows that the most abundant surface species is the adsorbed carbon monoxide in both cases. At the light-off temperature for the oxidation reaction of carbon monoxide over platinum, a relatively high concentration of the adsorbed atomic oxygen is obtained in the absence of hydrogen. This is due to the fact that the rate of the oxidation reaction of the adsorbed carbon monoxide with the adsorbed atomic oxygen on the surface of the catalyst is relatively low and no parallel reaction pathway exists under the conditions studied here. Conversely, the adsorbed atomic oxygen can be removed rapidly from the surface of the catalyst through the additional intermediate formate pathway in the presence of hydrogen. Consequently, the fractional coverage of the adsorbed atomic oxygen at the light-off temperature is significantly decreased, compared with that in the absence of hydrogen. While both the adsorbed atomic hydrogen and the surface hydroxyl group play an important role in the reaction mechanism, their concentrations on the surface of the catalyst are very low at the light-off temperature for the oxidation reaction of carbon monoxide over platinum. In spite of the very low concentrations of these important species, the oxidation reaction of carbon monoxide over platinum is promoted by the presence of a small amount of hydrogen in the feed, and the promoting effect is caused by the chemical routes relevant to hydrogen reactions, as discussed earlier. The very low level of the concentrations of these important species is caused by a surface chain reaction so that each of the atomic hydrogen elements adsorbed on the surface of the catalyst can be regenerated during the overall reaction of the propagation cycle, which is consistent with the experimental data reported in the literature [79]. Such a mechanism of the surface chain reaction is quite unusual in heterogeneous catalysis [80].

The activation energy barrier for the oxidation reaction of the adsorbed carbon monoxide with the hydroxyl group on the surface of the catalyst is lower than that with the adsorbed atomic oxygen. Consequently, hydrogen has a positive effect on the oxidation reaction of carbon monoxide over platinum, and lower light-off temperatures can be found under the conditions studied here. As the operating temperature is increased to a certain level, the direct oxidation of the adsorbed carbon monoxide by the adsorbed atomic oxygen is the main reaction pathway.

\section{Conclusions}

Low-temperature catalytic oxidation of syngas on platinum was investigated numerically for catalytic combustion gas turbine applications. A discussion about the detailed reaction mechanism existing in the literature was made for this low-temperature catalytic oxidation process. In order to provide guidance for the practical implementation of such design, the mechanism of this reaction was improved based on the latest available literature data, and essential steps in the reaction mechanism 
were finally identified. A numerical model with detailed chemistry and transport was developed that was capable of describing the low-temperature catalytic oxidation of carbon monoxide and hydrogen simultaneously.

It has been shown that the presence of hydrogen can significantly affect the adsorption behavior of the species on the surface of the catalyst at low temperatures. The hydrogen reaction routes are significant for predicting the promoting or inhibiting role of hydrogen in the low-temperature catalytic oxidation of carbon monoxide. The presence of hydrogen makes the active surface sites more available for adsorption, thus promoting the catalytic oxidation of carbon monoxide at temperatures as low as $600 \mathrm{~K}$. The coupling steps between hydrogen and carbon monoxide are unimportant. Interestingly, the presence of hydrogen can inhibit the catalytic oxidation of carbon monoxide at temperatures below $520 \mathrm{~K}$ due to the competitive adsorption of hydrogen and oxygen on the surface of the catalyst. This critical temperature is relevant to the part-load and idling operation in gas turbine systems.

The results would be helpful to understand the mechanism of the catalytic oxidation of syngas, which is vital to the design of syngas-fueled gas turbines, and the future development of integrated gasification combined cycle technology. Given the potential utilization of hydrogen in promoting or inhibiting the catalytic oxidation of carbon monoxide at low temperatures, the developed model could hopefully assist in the understanding and design of these power generation technologies. Finally, the identification of rate-determining step(s) could assist the improvement of catalysts.

Author Contributions: Conceptualization, J.C.; Methodology, J.C.; Software, L.Y.; Validation, W.S.; Formal Analysis, J.C.; Investigation, J.C.; Resources, D.X.; Supervision, J.C.; Project Administration, D.X.

Funding: This research was funded by the National Natural Science Foundation of China (No. 51506048) and the Fundamental Research Funds for the Universities of Henan Province (No. NSFRF140119).

Conflicts of Interest: The authors declare no conflict of interest.

\section{Nomenclature}

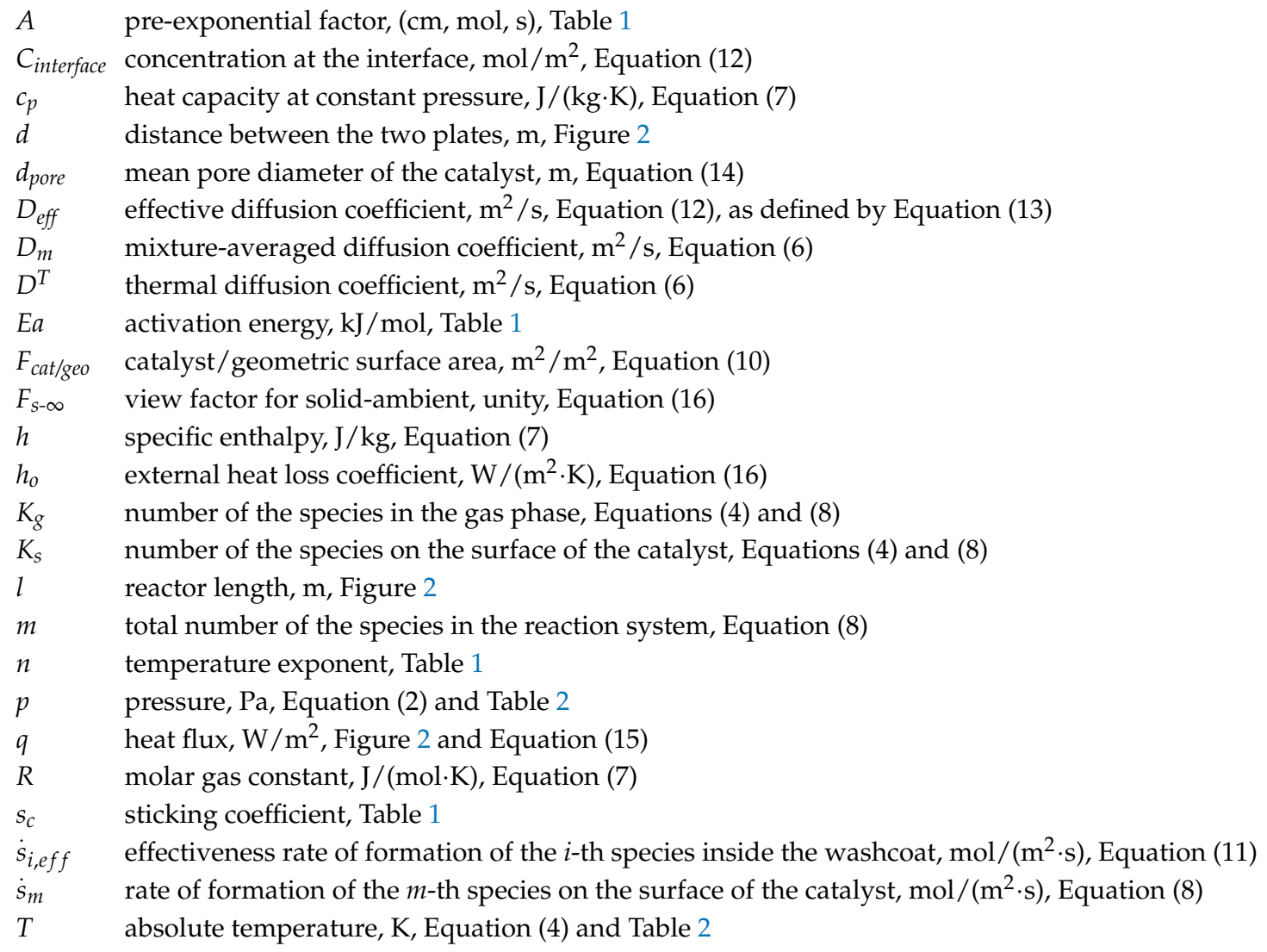


$T_{a m b}, T_{o}$ ambient and reference temperature, $K$, Equations (16) and (7)

$T_{w, 0} \quad$ temperature at the external surface of the wall, $\mathrm{K}$, Equation (16)

$u, v \quad$ streamwise and transverse velocity component, $\mathrm{m} / \mathrm{s}$, Equation (1) and Table 2

$V \quad$ diffusion velocity, $\mathrm{m} / \mathrm{s}$, Equation (5)

$\vec{V} \quad$ diffusion velocity vector, $\mathrm{m} / \mathrm{s}$, Equation (6)

$W \quad$ relative molecular mass, dimensionless, Equation (5)

$\bar{W} \quad$ relative molecular mass of the gas mixture, dimensionless, Equation (6)

$x, y \quad$ streamwise and transverse coordinate, Figure 2 and Equation (1)

$Y \quad$ mass fraction, Equation (4)

* an empty site or an adsorbed species, Table 1

\section{Greek variables}

$\beta \quad$ volume fraction, $\%$, Table 2

$\beta^{\prime} \quad$ temperature exponent, Equation (17)

$\Gamma \quad$ surface site density, $\mathrm{mol} / \mathrm{m}^{2}$, Equation (8)

$\gamma \quad$ catalytically active surface area per washcoat volume, $\mathrm{m}^{2} / \mathrm{m}^{3}$, Equation (12)

$\delta \quad$ thickness, m, Figure 2 and Equation (12)

$\varepsilon \quad$ emissivity, Equation (16)

$\varepsilon_{i} \quad$ coefficient for describing the rate coefficient on the surface coverage, $\Theta_{i}$, of species $i$, Equation (17)

$\varepsilon_{p} \quad$ catalyst porosity, dimensionless, Equation (13)

$\eta \quad$ effectiveness factor, Equation (10), as defined by Equation (11)

$\Theta_{i} \quad$ fractional coverage of the surface species $i$, i.e., surface coverage, Table 1

$\lambda \quad$ thermal conductivity, $\mathrm{W} /(\mathrm{m} \cdot \mathrm{K})$, Equation (4)

$\mu \quad$ dynamic viscosity, $\mathrm{kg} /(\mathrm{m} \cdot \mathrm{s})$, Equation (2)

$\mu_{i} \quad$ coefficient for describing the rate coefficient on the surface coverage, $\Theta_{i}$, of species $i$, Equation (17)

$\rho \quad$ density, $\mathrm{kg} / \mathrm{m}^{3}$, Equation (1)

$\sigma \quad$ Stefan-Boltzmann constant, $\mathrm{W} /\left(\mathrm{m}^{2} \cdot \mathrm{K}^{4}\right)$, Equation (16)

$\sigma_{m} \quad$ site occupancy of the $m$-th surface species, Equation (8)

$\tau_{p} \quad$ tortuosity factor, dimensionless, Equation (13)

$\varphi \quad$ equivalence ratio, Table 2

$\Phi \quad$ Thiele modulus, dimensionless, Equation (11), as defined by Equation (12)

$\dot{\omega}_{k} \quad$ rate of formation of the $k$-th species in the gas phase, $\mathrm{mol} /\left(\mathrm{m}^{3} \cdot \mathrm{s}\right)$, Equation (5)

\section{Subscripts}

g gas, Equation (4)

i species index, Equation (11)

in inlet, Table 2

$k, m \quad$ gaseous and surface species index, Equations (4) and (8)

$s, w \quad$ solid and wall, Equations (9) and (16)

$x, y \quad$ streamwise and transverse component, Equation (4)

\section{References}

1. Lan, W.; Chen, G.; Zhu, X.; Wang, X.; Liu, C.; Xu, B. Biomass gasification-gas turbine combustion for power generation system model based on ASPEN PLUS. Sci. Total Environ. 2018, 628-629, 1278-1286. [CrossRef]

2. Ghermay, Y.; Mantzaras, J.; Bombach, R. Experimental and numerical investigation of hetero-/homogeneous combustion of $\mathrm{CO} / \mathrm{H}_{2} / \mathrm{O}_{2} / \mathrm{N}_{2}$ mixtures over platinum at pressures up to 5 bar. Proc. Combust. Inst. 2011, 33, 1827-1835. [CrossRef]

3. Zheng, X.; Mantzaras, J.; Bombach, R. Homogeneous combustion of fuel-lean syngas mixtures over platinum at elevated pressures and preheats. Combust. Flame 2013, 160, 155-169. [CrossRef]

4. Pramanik, S.; Ravikrishna, R.V. Numerical study of rich catalytic combustion of syngas. Int. J. Hydrogen Energy 2017, 42, 16514-16528. [CrossRef]

5. Gong, X.; Wang, W.-W.; Fu, X.-P.; Wei, S.; Yu, W.-Z.; Liu, B.; Jia, C.-J.; Zhang, J. Metal-organic-framework derived controllable synthesis of mesoporous copper-cerium oxide composite catalysts for the preferential oxidation of carbon monoxide. Fuel 2018, 229, 217-226. [CrossRef] 
6. Sengodan, S.; Lan, R.; Humphreys, J.; Du, D.; Xu, W.; Wang, H.; Tao, S. Advances in reforming and partial oxidation of hydrocarbons for hydrogen production and fuel cell applications. Renew. Sustain. Energy Rev. 2018, 82, 761-780. [CrossRef]

7. Mantzaras, J. Catalytic combustion of syngas. Combust. Sci. Technol. 2008, 180, 1137-1168. [CrossRef]

8. Federici, J.A.; Vlachos, D.G. Experimental studies on syngas catalytic combustion on $\mathrm{Pt} / \mathrm{Al}_{2} \mathrm{O}_{3}$ in a microreactor. Combust. Flame 2011, 158, 2540-2543. [CrossRef]

9. Sui, R.; Es-Sebbar, E.-T.; Mantzaras, J.; Prasianakis, N.I. Experimental and numerical investigation of fuel-lean $\mathrm{H}_{2} / \mathrm{CO} /$ air and $\mathrm{H}_{2} / \mathrm{CH}_{4}$ /air catalytic microreactors. Combust. Sci. Technol. 2018, 190, 336-362. [CrossRef]

10. Zheng, X.; Mantzaras, J.; Bombach, R. Kinetic interactions between hydrogen and carbon monoxide oxidation over platinum. Combust. Flame 2014, 161, 332-346. [CrossRef]

11. Harun, N.F.; Tucker, D.; Adams, T.A., II. Technical challenges in operating an SOFC in fuel flexible gas turbine hybrid systems: Coupling effects of cathode air mass flow. Appl. Energy 2017, 190, 852-867. [CrossRef]

12. Harun, N.F.; Tucker, D.; Adams II, T.A. Impact of fuel composition transients on SOFC performance in gas turbine hybrid systems. Appl. Energy 2016, 164, 446-461. [CrossRef]

13. Mantzaras, J. Evaluation of models for heterogeneous catalysis. In Modeling and Simulation of Heterogeneous Catalytic Reactions; Lieuwen, T., Yang, V., Yetter, R., Eds.; CRC Press: Boca Raton, FL, USA, 2010; Chapter 8, pp. 223-260; ISBN 978-1-4200-8534-1.

14. Fumey, B.; Buetler, T.; Vogt, U.F. Ultra-low NOx emissions from catalytic hydrogen combustion. Appl. Energy 2018, 213, 334-342. [CrossRef]

15. Fanciulli, C.; Abedi, H.; Merotto, L.; Dondè, R.; de Iuliis, S.; Passaretti, F. Portable thermoelectric power generation based on catalytic combustor for low power electronic equipment. Appl. Energy 2018, 215, 300-308. [CrossRef]

16. Zheng, X.; Schultze, M.; Mantzaras, J.; Bombach, R. Effects of hydrogen addition on the catalytic oxidation of carbon monoxide over platinum at power generation relevant temperatures. Proc. Combust. Inst. 2013, 34, 3343-3350. [CrossRef]

17. Bin, F.; Wei, X.; Li, T.; Liu, D.; Hao, Q.; Dou, B. Self-sustained catalytic combustion of carbon monoxide ignited by dielectric barrier discharge. Proc. Combust. Inst. 2017, 36, 4193-4200. [CrossRef]

18. Gan, Y.; Tong, Y.; Jiang, Z.; Chen, X.; Li, H.; Jiang, X. Electro-spraying and catalytic combustion characteristics of ethanol in meso-scale combustors with steel and platinum meshes. Energy Convers. Manag. 2018, 164, 410-416. [CrossRef]

19. Li, Y.-H.; Hong, J.-R. Performance assessment of catalytic combustion-driven thermophotovoltaic platinum tubular reactor. Appl. Energy 2018, 211, 843-853. [CrossRef]

20. Kunte, A.; Raghu, A.K.; Kaisare, N.S. A spiral microreactor for improved stability and performance for catalytic combustion of propane. Chem. Eng. Sci. 2018, 187, 87-97. [CrossRef]

21. Tolmachoff, E.D.; Allmon, W.; Waits, C.M. Analysis of a high throughput n-dodecane fueled heterogeneous/homogeneous parallel plate microreactor for portable power conversion. Appl. Energy 2014, 128, 111-118. [CrossRef]

22. Merotto, L.; Fanciulli, C.; Dondè, R.; De Iuliis, S. Study of a thermoelectric generator based on a catalytic premixed meso-scale combustor. Appl. Energy 2016, 162, 346-353. [CrossRef]

23. Federici, J.A.; Norton, D.G.; Brüggemann, T.; Voit, K.W.; Wetzel, E.D.; Vlachos, D.G. Catalytic microcombustors with integrated thermoelectric elements for portable power production. J. Power Sources 2006, 161, 1469-1478. [CrossRef]

24. Giarratano, F.; Arzac, G.M.; Godinho, V.; Hufschmidt, D.; de Haro, M.C.J.; Montes, O.; Fernández, A. Nanoporous Pt-based catalysts prepared by chemical dealloying of magnetron-sputtered Pt-Cu thin films for the catalytic combustion of hydrogen. Appl. Catal. B 2018, 235, 168-176. [CrossRef]

25. Sui, R.; Mantzaras, J.; Bombach, R. A comparative experimental and numerical investigation of the heterogeneous and homogeneous combustion characteristics of fuel-rich methane mixtures over rhodium and platinum. Proc. Combust. Inst. 2017, 36, 4313-4320. [CrossRef]

26. Sui, R.; Mantzaras, J. Combustion stability and hetero-/homogeneous chemistry interactions for fuel-lean hydrogen/air mixtures in platinum-coated microchannels. Combust. Flame 2016, 173, 370-386. [CrossRef]

27. Di Sarli, V.; Barbato, P.S.; Di Benedetto, A.; Landi, G. Start-up behavior of a $\mathrm{LaMnO}_{3}$ partially coated monolithic combustor at high pressure. Catal. Today 2015, 200-210. [CrossRef] 
28. Pocoroba, E.; Johansson, E.M.; Järås, S.G. Ageing of palladium, platinum and manganese-based combustion catalysts for biogas applications. Catal. Today 2000, 59, 179-189. [CrossRef]

29. Varghese, R.J.; Kolekar, H.; Hariharan, V.; Kumar, S. Effect of CO content on laminar burning velocities of syngas-air premixed flames at elevated temperatures. Fuel 2018, 214, 144-153. [CrossRef]

30. Wang, J.; Nie, Y.; Cai, X.; Guo, S.; Zhang, W.; Xie, Y.; Huang, Z. Investigation on the highly negative curved syngas Bunsen flame and the critical local Karlovitz number when tip opening. Fuel 2018, 215, 429-437. [CrossRef]

31. Carltonbird, M.; Eaimsumang, S.; Pongstabodee, S.; Boonyuen, S.; Smith, S.M.; Luengnaruemitchai, A. Effect of the exposed ceria morphology on the catalytic activity of gold/ceria catalysts for the preferential oxidation of carbon monoxide. Chem. Eng. J. 2018, 344, 545-555. [CrossRef]

32. Yeste, M.P.; Vidal, H.; García-Cabeza, A.L.; Hernández-Garrido, J.C.; Guerra, F.M.; Cifredo, G.A.; González-Leal, J.M.; Gatica, J.M. Low temperature prepared copper-iron mixed oxides for the selective CO oxidation in the presence of hydrogen. Appl. Catal. A 2018, 552, 58-69. [CrossRef]

33. Jampa, S.; Wangkawee, K.; Tantisriyanurak, S.; Changpradit, J.; Jamieson, A.M.; Chaisuwan, T.; Luengnaruemitchai, A.; Wongkasemjit, S. High performance and stability of copper loading on mesoporous ceria catalyst for preferential oxidation of CO in presence of excess of hydrogen. Int. J. Hydrogen Energy 2017, 42, 5537-5548. [CrossRef]

34. Rankovic, N.; Nicolle, A.; Berthout, D.; Costa, P.D. Kinetic modeling study of the oxidation of carbon monoxide-hydrogen mixtures over $\mathrm{Pt} / \mathrm{Al}_{2} \mathrm{O}_{3}$ and $\mathrm{Rh} / \mathrm{Al}_{2} \mathrm{O}_{3}$ catalysts. J. Phys. Chem. C 2011, 115, 20225-20236. [CrossRef]

35. Paz, D.S.; Damyanova, S.; Borges, L.R.; Santos, J.B.O.; Bueno, J.M.C. Identifying the adsorbed active intermediates on $\mathrm{Pt}$ surface and promotion of activity through the redox $\mathrm{CeO}_{2}$ in preferential oxidation of $\mathrm{CO}$ in $\mathrm{H}_{2}$. Appl. Catal. A 2017, 548, 164-178. [CrossRef]

36. Salomons, S.; Hayes, R.E.; Votsmeier, M. The promotion of carbon monoxide oxidation by hydrogen on supported platinum catalyst. Appl. Catal. A 2009, 352, 27-34. [CrossRef]

37. Salomons, S.; Votsmeier, M.; Hayes, R.E.; Drochner, A.; Vogel, H.; Gieshoff, J. CO and $\mathrm{H}_{2}$ oxidation on a platinum monolith diesel oxidation catalyst. Catal. Today 2006, 117, 491-497. [CrossRef]

38. Moretti, E.; Rodríguez-Aguado, E.; Infantes-Molina, A.; Rodríguez-Castellón, E.; Talon, A.; Storaro, L. Sustainable photo-assisted $\mathrm{CO}$ oxidation in $\mathrm{H}_{2}$-rich stream by simulated solar light response of $\mathrm{Au}$ nanoparticles supported on $\mathrm{TiO}_{2}$. Catal. Today 2018, 304, 135-142. [CrossRef]

39. Landi, G.; Barbato, P.S.; Di Benedetto, A.; Pirone, R.; Russo, G. High pressure kinetics of $\mathrm{CH}_{4}, \mathrm{CO}$ and $\mathrm{H}_{2}$ combustion over $\mathrm{LaMnO}_{3}$ catalyst. Appl. Catal. B 2013, 134-135, 110-122. [CrossRef]

40. Kéromnès, A.; Metcalfe, W.K.; Heufer, K.A.; Donohoe, N.; Das, A.K.; Sung, C.-J.; Herzler, J.; Naumann, C.; Griebel, P.; Mathieu, O.; et al. An experimental and detailed chemical kinetic modeling study of hydrogen and syngas mixture oxidation at elevated pressures. Combust. Flame 2013, 160, 995-1011. [CrossRef]

41. Xu, H.; Sun, S.; Liu, F.; Zhao, Y.; Liu, Y.; Chen, L.; Meng, S. An experimental and computational study of $\mathrm{OH}$ formation in laminar coflow syngas diffusion flames. Fuel 2018, 225, 47-53. [CrossRef]

42. Thi, L.D.; Zhang, Y.; Huang, Z. Shock tube study on ignition delay of multi-component syngas mixtures-Effect of equivalence ratio. Int. J. Hydrogen Energy 2014, 39, 6034-6043. [CrossRef]

43. Ilbas, M.; Sahin, M. Effects of turbulator angle and hydrogen addition on a biogas turbulent diffusion flame. Int. J. Hydrogen Energy 2017, 42, 25735-25743. [CrossRef]

44. Ilbas, M.; Karyeyen, S. Turbulent diffusion flames of a low-calorific value syngas under varying turbulator angles. Energy 2017, 138, 383-393. [CrossRef]

45. Samiran, N.A.; Ng, J.-H.; Jaafar, M.N.M.; Valera-Medina, A.; Chong, C.T. Swirl stability and emission characteristics of CO-enriched syngas/air flame in a premixed swirl burner. Process Saf. Environ. 2017, 112, 315-326. [CrossRef]

46. Jafargholi, M.; Giannakopoulos, G.K.; Frouzakis, C.E.; Boulouchos, K. Laminar syngas-air premixed flames in a closed rectangular domain: DNS of flame propagation and flame/wall interactions. Combust. Flame 2018, 188, 453-468. [CrossRef]

47. Sun, K.; Kohyama, M.; Tanaka, S.; Takeda, S. Roles of water and $\mathrm{H}_{2}$ in $\mathrm{CO}$ oxidation reaction on gold catalysts. J. Phys. Chem. C 2018, 122, 9523-9530. [CrossRef]

48. Betta, R.A.D. Catalytic combustion gas turbine systems: The preferred technology for low emissions electric power production and co-generation. Catal. Today 1997, 35, 129-135. [CrossRef] 
49. Carroni, R.; Schmidt, V.; Griffin, T. Catalytic combustion for power generation. Catal. Today 2002, 75, $287-295$. [CrossRef]

50. Cocchi, S.; Nutini, G.; Spencer, M.J.; Nickolas, S.G. Catalytic combustion system for a $10 \mathrm{MW}$ class power generation gas turbine. Catal. Today 2006, 117, 419-426. [CrossRef]

51. Westbrook, C.K.; Mizobuchi, Y.; Poinsot, T.J.; Smith, P.J.; Warnatz, J. Computational combustion. Proc. Combust. Inst. 2005, 30, 125-157. [CrossRef]

52. Gonzalez-Juez, E.D.; Kerstein, A.R.; Ranjan, R.; Menon, S. Advances and challenges in modeling high-speed turbulent combustion in propulsion systems. Prog. Energy Combust. Sci. 2017, 60, 26-67. [CrossRef]

53. Arani, B.O.; Frouzakis, C.E.; Mantzaras, J.; Lucci, F.; Boulouchos, K. Direct numerical simulation of turbulent channel-flow catalytic combustion: Effects of Reynolds number and catalytic reactivity. Combust. Flame 2018, 187, 52-66. [CrossRef]

54. Chiuta, S.; Bessarabov, D.G. Design and operation of an ammonia-fueled microchannel reactor for autothermal hydrogen production. Catal. Today 2018, 310, 187-194. [CrossRef]

55. Delparish, A.; Avci, A.K. Modeling of intensified glycerol steam reforming in a heat-exchange integrated microchannel reactor. Catal. Today 2018, 299, 328-338. [CrossRef]

56. Li, W.-L.; Ouyang, Y.; Gao, X.-Y.; Wang, C.-Y.; Shao, L.; Xiang, Y. CFD analysis of gas-liquid flow characteristics in a microporous tube-in-tube microchannel reactor. Comput. Fluids 2018, 170, 13-23. [CrossRef]

57. Sattari-Najafabadi, M.; Esfahany, M.N.; Wu, Z.; Sunden, B. Mass transfer between phases in microchannels: A review. Chem. Eng. Process. Process Intensif. 2018, 127, 213-237. [CrossRef]

58. Bac, S.; Keskin, S.; Avci, A.K. Modeling and simulation of water-gas shift in a heat exchange integrated microchannel converter. Int. J. Hydrogen Energy 2018, 43, 1094-1104. [CrossRef]

59. ANSYS Fluent User's Guide; Release 16.0; ANSYS Inc.: Canonsburg, PA, USA, 2014.

60. Deutschmann, O. Modeling of the interactions between catalytic surfaces and gas-phase. Catal. Lett. 2015, 145, 272-289. [CrossRef]

61. Bergman, T.L.; Lavine, A.S.; Incropera, F.P.; DeWitt, D.P. Fundamentals of Heat and Mass Transfer, 7th ed.; John Wiley \& Sons, Inc.: Hoboken, NJ, USA, 2011; ISBN 978-0-470-50197-9.

62. Hunt, G.; Torabi, M.; Govone, L.; Karimi, N.; Mehdizadeh, A. Two-dimensional heat and mass transfer and thermodynamic analyses of porous microreactors with Soret and thermal radiation effects-An analytical approach. Chem. Eng. Process. Process Intensif. 2018, 126, 190-205. [CrossRef]

63. Deutschmann, O.; Maier, L.I.; Riedel, U.; Stroemman, A.H.; Dibble, R.W. Hydrogen assisted catalytic combustion of methane on platinum. Catal. Today 2000, 59, 141-150. [CrossRef]

64. Koop, J.; Deutschmann, O. Detailed surface reaction mechanism for Pt-catalyzed abatement of automotive exhaust gases. Appl. Catal. B 2009, 91, 47-58. [CrossRef]

65. Li, J.; Zhao, Z.; Kazakov, A.; Chaos, M.; Dryer, F.L.; Scire, J.J., Jr. A comprehensive kinetic mechanism for CO, $\mathrm{CH}_{2} \mathrm{O}$, and $\mathrm{CH}_{3} \mathrm{OH}$ combustion. Int. J. Chem. Kinet. 2007, 39, 109-136. [CrossRef]

66. Burke, M.P.; Chaos, M.; Ju, Y.; Dryer, F.L.; Klippenstein, S.J. Comprehensive $\mathrm{H}_{2} / \mathrm{O}_{2}$ kinetic model for high-pressure combustion. Int. J. Chem. Kinet. 2012, 44, 444-474. [CrossRef]

67. Kee, R.J.; Rupley, F.M.; Meeks, E.; Miller, J.A. CHEMKIN-III: A Fortran Chemical Kinetics Package for the Analysis of Gasphase Chemical and Plasma Kinetics; Report No. SAND96-8216; Sandia National Laboratories: Livermore, CA, USA, 1996.

68. Coltrin, M.E.; Kee, R.J.; Rupley, F.M.; Meeks, E. SURFACE CHEMKIN-III: A Fortran Package for Analyzing Heterogeneous Chemical Kinetics at a Solid-Surface-Gas-Phase Interface; Report No. SAND96-8217; Sandia National Laboratories: Livermore, CA, USA, 1996.

69. Kee, R.J.; Dixon-lewis, G.; Warnatz, J.; Coltrin, M.E.; Miller, J.A.; Moffat, H.K. A Fortran Computer Code Package for the Evaluation of Gas-Phase, Multicomponent Transport Properties; Report No. SAND86-8246B; Sandia National Laboratories: Livermore, CA, USA, 1998.

70. Bhatia, D.; Harold, M.P.; Balakotaiah, V. Kinetic and bifurcation analysis of the cooxidation of $\mathrm{CO}$ and $\mathrm{H}_{2}$ in catalytic monolith reactors. Chem. Eng. Sci. 2009, 64, 1544-1558. [CrossRef]

71. Bu, Y.; Er, S.; Niemantsverdriet, J.W.H.; Fredriksson, H.O.A. Preferential oxidation of $\mathrm{CO}$ in $\mathrm{H}_{2}$ on $\mathrm{Cu}$ and $\mathrm{Cu} / \mathrm{CeOx}$ catalysts studied by in situ UV-Vis and mass spectrometry and DFT. J. Catal. 2018, 357, 176-187. [CrossRef] 
72. Van Spronsen, M.A.; Frenken, J.W.M.; Groot, I.M.N. Surface science under reaction conditions: CO oxidation on Pt and Pd model catalysts. Chem. Soc. Rev. 2017, 46, 4347-4374. [CrossRef] [PubMed]

73. Tang, A.; Cai, T.; Deng, J.; Xu, Y.; Pan, J. Experimental investigation on combustion characteristics of premixed propane/air in a micro-planar heat recirculation combustor. Energy Convers. Manag. 2017, 152, 65-71. [CrossRef]

74. Blomberg, S.; Zetterberg, J.; Zhou, J.; Merte, L.R.; Gustafson, J.; Shipilin, M.; Trinchero, A.; Miccio, L.A.; Magaña, A.; Ilyn, M.; et al. Strain dependent light-off temperature in catalysis revealed by planar laser-induced fluorescence. ACS Catal. 2017, 7, 110-114. [CrossRef]

75. Rodríguez, M.L.; Cadús, L.E. Mass transfer limitations in a monolithic reactor for the catalytic oxidation of ethanol. Chem. Eng. Sci. 2016, 143, 305-313. [CrossRef]

76. Van Daele, T.; del Pozo, D.F.; van Hauwermeiren, D.; Gernaey, K.V.; Wohlgemuth, R.; Nopens, I. A generic model-based methodology for quantification of mass transfer limitations in microreactors. Chem. Eng. J. 2016, 300, 193-208. [CrossRef]

77. Stegelmann, C.; Andreasen, A.; Campbell, C.T. Degree of rate control: How much the energies of intermediates and transition states control rates. J. Am. Chem. Soc. 2009, 131, 8077-8082. [CrossRef] [PubMed]

78. Campbell, C.T. The degree of rate control: A powerful tool for catalysis research. ACS Catal. 2017, 7, 2770-2779. [CrossRef]

79. Choi, J.; Pan, L.; Mehar, V.; Zhang, F.; Asthagiri, A.; Weaver, J.F. Promotion of CO oxidation on PdO (101) by adsorbed $\mathrm{H}_{2}$ O. Surf. Sci. 2016, 650, 203-209. [CrossRef]

80. Boronat, M.; Concepción, P. Combined theoretical and spectroscopic mechanistic studies for improving activity and selectivity in heterogeneous catalysis. Catal. Today 2017, 285, 166-178. [CrossRef]

(C) 2018 by the authors. Licensee MDPI, Basel, Switzerland. This article is an open access article distributed under the terms and conditions of the Creative Commons Attribution (CC BY) license (http:/ / creativecommons.org/licenses/by/4.0/). 